\title{
Similarities and interactions between the ageing process and high chronic intake of added sugars
}

\author{
Eva Gatineau ${ }^{1,2}$, Sergio Polakof ${ }^{1,2}$, Dominique Dardevet $^{1,2}$ and Laurent Mosoni ${ }^{1,2 *}$ \\ ${ }^{1}$ INRA, UMR 1019 Nutrition Humaine, F-63122 Saint Genès Champanelle, France \\ ${ }^{2}$ Univ Clermont 1, UFR Médecine, UMR 1019 Nutrition Humaine, F-63000 Clermont-Ferrand, France
}

\section{Abstract}

In our societies, the proportions of elderly people and of obese individuals are increasing. Both factors are associated with high health-related costs. During obesity, many authors suggest that it is a high chronic intake of added sugars (HCIAS) that triggers the shift towards pathology. However, the majority of studies were performed in young subjects and only a few were interested in the interaction with the ageing process. Our purpose was to discuss the metabolic effects of HCIAS, compare with the effects of ageing, and evaluate how deleterious the combined action of HCIAS and ageing could be. This effect of HCIAS seems mediated by fructose, targeting the liver first, which may lead to all subsequent metabolic alterations. The first basic alterations induced by fructose are increased oxidative stress, protein glycation, inflammation, dyslipidaemia and insulin resistance. These alterations are also present during the ageing process, and are closely related to each other, one leading to the other. These basic alterations are also involved in more complex syndromes, which are also favoured by HCIAS, and present during ageing. These include non-alcoholic fatty liver disease, hypertension, neurodegenerative diseases, sarcopenia and osteoporosis. Cumulative effects of ageing and HCIAS have been seldom tested and may not always be strictly additive. Data also suggest that some of the metabolic alterations that are more prevalent during ageing could be related more with nutritional habits than to intrinsic ageing. In conclusion, it is clear that HCIAS interacts with the ageing process, accelerates the accumulation of metabolic alterations, and that it should be avoided.

\section{Key words: Fructose: Ageing: Lipids: Liver: Inflammation: Oxidative stress: Insulin}

\section{Introduction}

In most of the countries of the world, the characteristics of the populations are currently being modified in a double way: the proportion of elderly people is increasing, as well as the proportion of obese individuals. The proportion of the world's population aged 60 years or over increased from $8 \%$ in 1950 to $12 \%$ in 2013 and could reach $21 \%$ by 2050 , representing approximately 2 billion people ${ }^{(1)}$. Regarding obesity, in 1975 , $3.2 \%$ of men and $6.4 \%$ of women were obese (BMI $>30 \mathrm{~kg} / \mathrm{m}^{2}$ ) in the world. In 2014, it was $10.8 \%$ of men and $14.9 \%$ of women. In 2025 , it could reach $18 \%$ for men, and more than $21 \%$ for women ${ }^{(2)}$.

A common denominator certainly plays a role in these evolutions, an increase in food availability. Nowadays, all nutrient needs are easily covered at all ages for a high proportion of the population in most countries, which favours successful ageing (i.e. good health and quality of life) and an increase in the proportion of elderly subjects; but excessive food intake may also lead to obesity.
Both conditions (being old and being obese) are dangerous for health. Ageing can be defined as a decrease in the capacity to maintain homeostasis, a progressive loss of physiological integrity, leading to impaired function and increased vulnerability to death ${ }^{(3)}$. Similarly, obesity constitutes one of the criteria of the metabolic syndrome along with hypertension, dyslipidaemia (high TAG, high total cholesterol, low HDLcholesterol) and hyperglycaemia. The metabolic syndrome leads to increased risks of type 2 diabetes, CHD and stroke.

Since the development of obesity is relatively recent, and is occurring in a world with an increased proportion of elderly subjects, it is logical to think that we will be more and more confronted with the combination of both effects. Since obesity is deleterious, it may prevent successful ageing and reduce life expectancy. For instance, it was estimated that in the USA, the high prevalence of obesity explains at least $20-35 \%$ of the shortfall in US life expectancy relative to countries with superior levels ${ }^{(4)}$. If obesity continues to rise in the USA or in other countries, although many factors affect the calculation of life expectancy, it could slow or even stop the observed constant

Abbreviations: A $\beta, \beta$-amyloid; AGE, advanced glycation endproducts; APP, $\beta$-amyloid precursor protein; ChREBP, carbohydrate-response element-binding protein; CRP, C-reactive protein; DNL, de novo lipogenesis; HCIAS, high chronic intake of added sugars; IR, insulin receptor; IRS, insulin receptor substrate; JNK, c-Jun N-terminal kinase; NAFLD, non-alcoholic fatty liver disease; ROS, reactive oxygen species; SOD, superoxide dismutase; SREBP, sterol regulatory response element-binding protein.

* Corresponding author: Laurent Mosoni, fax +334736247 55, email laurent.mosoni@clermont.inra.fr 


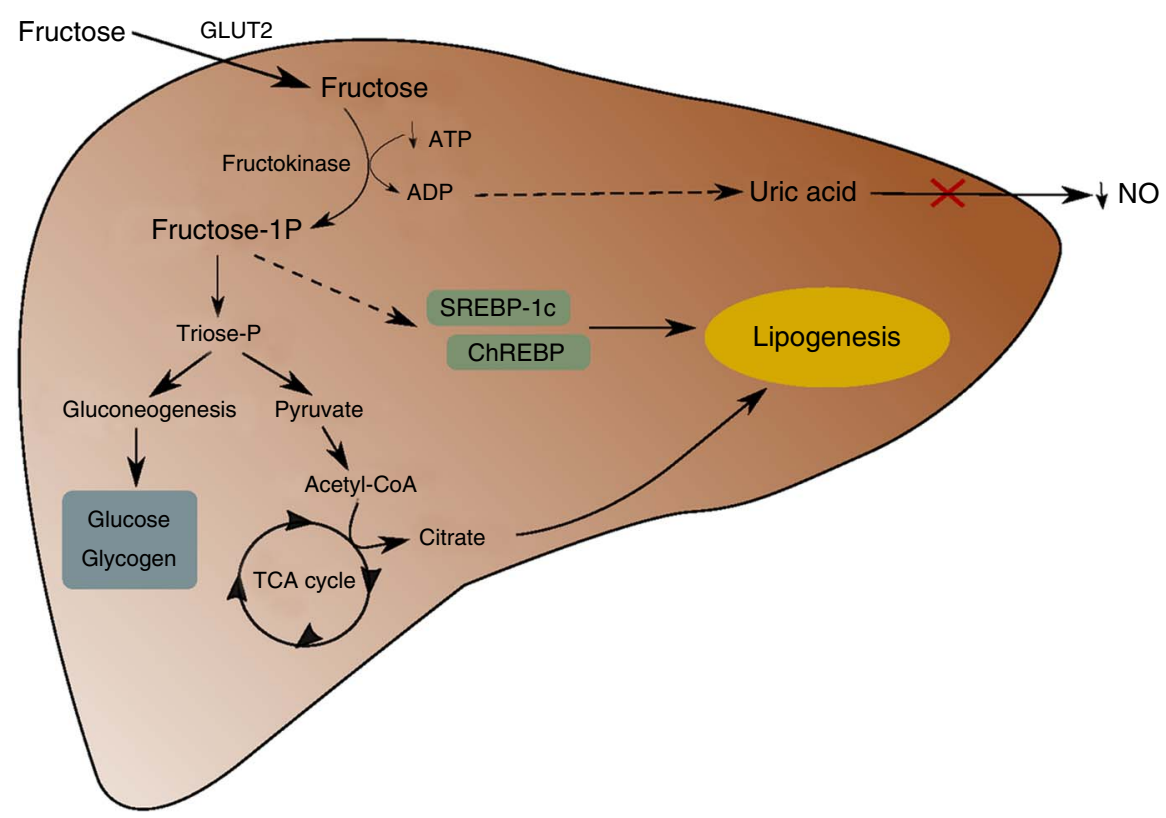

Fig. 1. Fructose liver metabolism. SREPB-1c, sterol regulatory element-binding protein; ChREBP, carbohydrate responsive element-binding protein.

increase in life expectancy that is currently observed all over the world.

Another parameter must be included in the equation: 'added sugar' consumption. Obese individuals often (but not always) consume a high amount of added sugars. It contributes to their excess of energy intake, but many authors suggest that such a high chronic intake of added sugars (HCIAS) is also responsible for the pathological complications of obesity. The pathologies and risk factors commonly attributed to obesity should be in fact associated with HCIAS ${ }^{(5)}$. The expression 'added sugars' refers to any sweetener containing the molecule fructose (like sucrose) that is added to food in processing. Thus, this definition does not include fructose present in fruits and honey whose consumption is positively associated with health in relation with protective nutrients that are also present in these foods (vitamins, antioxidants, polyphenols, fibres). Over the past decades, the consumption of such 'added sugars' has been steadily increasing. Fructose consumption constitutes today more than $9 \%$ of total energy intake in the USA. HCIAS will lead to the apparition of pathologies such as hypertension, diabetes and heart diseases. This is due to the specificities of fructose metabolism.

Indeed, contrary to glucose, the vast majority of ingested fructose is metabolised in the liver and does not reach peripheral organs (Fig. 1). In the liver, fructose is quickly and efficiently phosphorylated into fructose-1P under the action of fructokinase, with the consumption of $\mathrm{ATP}^{(6)}$. Fructokinase is highly specific for fructose and is not regulated by insulin. In addition, contrary to what is observed for lipolysis, fructolytic enzymes are not inhibited by their products. Consequently, all of the fructose present in the hepatocyte is phosphorylated, which leads to a depletion in the intracellular ATP pool, resulting in uric acid production, potentially deleterious for cells ${ }^{(7)}$. Fructose-1P is then metabolised into triose-P, mostly converted into glucose and glycogen through gluconeogenesis ${ }^{(8)}$. Also, triose-P can be converted into pyruvate and then into acetyl-CoA which can be used as a substrate for de novo lipogenesis (DNL) after conversion into citrate through the tricarboxylic acid cycle, leading to de novo synthesis and secretion of $\mathrm{TAG}^{(9)}$. Moreover, fructose is able to increase the abundance of two transcription factors that regulate lipogenesis: the sterol regulatory response element-binding protein-1c (SREBP-1c) and the carbohydrateresponse element-binding protein (ChREBP): in turn, these transcription factors activate lipogenesis by increasing the expression of enzymes like ATP-citrate lyase, acetyl-CoA carboxylase, fatty acid synthase, pyruvate kinase and glycerol3 -phosphate acyltransferase ${ }^{(10)}$. Excessive intake of fructose, through this stimulation of lipogenesis, can then lead to the development of several disorders ${ }^{(11)}$, like an increase in oxidative stress, protein glycation, inflammation, dyslipidaemia and insulin resistance. These alterations are also characteristic features of ageing. In fact, as we will discover in the present review, many of the deleterious effects of fructose consumption are similar to the effects of ageing. Fructose seems to mimic the effect of ageing. The ageing process is the result of the effects of the deleterious factors that are present in our environment, genetic programming, and the interaction between the two. Based on the similarities between metabolic diseases induced by HCIAS and observed during ageing, it seems clear that HCIAS is one of these deleterious factors of our environment, and that it can accelerate ageing in the sense that the 'physiological age' of subjects that are having a HCIAS may be older than their 'chronological age'. Thus, in a world with an increased proportion of elderly individuals, an increase in fructose consumption could have deleterious effects and contribute to a further reduction in life expectancy. 
Comparative deleterious effects of ageing and high chronic intake of 'added sugar'

Studies available to assess the health-related effects of fructose are mainly either human studies or rodent studies. Human studies can be epidemiological studies or intervention studies. The difficulty associated with human studies is the great number of possible confounding factors (other components of the diet, genetic diversity, lifestyle, etc.). In particular, in human studies, high fructose intake is very often associated with an excess of energy intake, either as fructose, or as fat, which tends to exacerbate deleterious effects of fructose. On the contrary, in rodent studies, confounding factors are reduced to a minimum, and each component of the diet is controlled. However, many of these rodent studies use very high levels of fructose or sucrose in the diet, much higher than what can be attained in the human diet, by replacing all the starch by fructose or sucrose. However, there is no overfeeding in these studies, and the effect of fructose can be exacerbated by the dose but not by a concomitant excessive energy intake as is often the case in human studies. In other animal studies, fructose can be included in the drinking water, which is much closer to the human situation in term of dose, but, in that case, the extra energy that is provided by fructose is most of the time not taken into account. Very few studies used a reasonable exchange of starch with fructose or sucrose, thus controlling total energy intake and using a dose of fructose comparable with the human situation. In the following sections, for animal studies, we will point out when added sugars were included in the drinking water or when reasonable amounts of fructose were included in solid food. It can be assumed that in all the other animal studies that we quote, high amounts of fructose or sucrose were used.

\section{Basic alterations}

Oxidative stress, protein glycation, inflammation, dyslipidaemia and insulin resistance are alterations that are observed during ageing and during HCIAS. These alterations are highly linked with each other and probably play a major role in the development of secondary diseases.

Oxidative stress. It is now well known that production of oxidative species increases during ageing. In particular, this increase has been reported in mitochondria, which is the main cellular source of reactive oxygen species (ROS), along the electron transport chain. It has been observed in old rats in muscle $^{(12)}$, liver ${ }^{(13)}$, heart ${ }^{(14)}$ and brain ${ }^{(15)}$. In addition, ageing is associated with a decrease in antioxidant activities. This decrease is partially explained by an alteration of the Nrf2 pathway, involved in the regulation of several antioxidant enzymes such as superoxide dismutase (SOD), catalase and glutathione peroxidase $(\mathrm{GPx})^{(16)}$. Activities of these enzymes decrease with age although there are some variations between tissues. For example, Pansarasa et al. ${ }^{(17)}$ described a decrease in the total activity of SOD in the muscle of old men, while Stojkovski et al. ${ }^{(18)}$ obtained an increase in mitochondrial SOD activity in the brain and liver in old rats. Yet, in this last study, despite this increase in SOD activity, the effect of $\alpha$-tocopherol treatment on the prevention of heat exposure-induced oxidative stress was decreased in liver mitochondria of old rats. Overall, these results, in line with other data from Zhang et $a{ }^{(19)}$, suggest that aged rats seem less able to cope with oxidative stress. However, age-related oxidative imbalance is not systematic, and seems highly dependent on environmental factors and not only on age.

In particular, HCIAS has been shown to induce an alteration of redox status. A decrease in the reduced/oxidised glutathione ratio (GSH:GSSG) was observed in erythrocytes following a high-fructose diet consumption ${ }^{(20)}$. Blood total antioxidant status is also decreased by a high-sucrose diet in rats, as well as SOD and GPX activities in erythrocytes, whereas plasma thiobarbituric acid-reactive substances (TBARS) concentration is increased in rats ${ }^{(21)}$. HCIAS-induced oxidative stress is present in several tissues including liver. For instance, in rat liver, after consumption of drinking water containing sucrose, $\mathrm{H}_{2} \mathrm{O}_{2}$ generation was increased in mitochondria, as well as TBARS, and protein carbonyl concentration, and gene and protein expression of catalase and SOD were decreased ${ }^{(22,23)}$. A fructose-induced increase in oxidative stress was also observed in rat heart ${ }^{(24)}$, rat pancreas ${ }^{(25)}$ and L6 skeletal muscle cells ${ }^{(26)}$.

HCIAS-induced oxidative stress could also be due to NADPH oxidases (Nox). Indeed in isolated rat aorta, fructose induced an overactivation of Nox that enhanced superoxide anion production $^{(27)}$. Nox are another source of cellular ROS responsible for superoxide production by transferring electrons across the membrane from NADPH to molecular oxygen, and could also be involved in cellular senescence, notably through the overexpression of Nox $4^{(28)}$. NADPH oxidase activity in arteries was also stimulated by fructose intake in ApoE-KO mice ${ }^{(29)}$.

So, HCIAS is able to induce an alteration in redox status comparable with the effect of ageing, since it leads to a decrease in antioxidant capacities and an increase in ROS production. This oxidative stress could result mainly from an increased mitochondrial production of free radicals, but has probably other origins too, in interaction with inflammation (see below) and insulin resistance. It is thus very similar to the ageing process. To our knowledge, very few studies analysed the cumulative effects of ageing and HCIAS. It is clear, though, that HCIAS is a way to increase oxidative stress during ageing.

Protein glycation. Like oxidative stress, advanced glycation endproducts (AGE) could be involved in age-related functional decline in organisms ${ }^{(30)}$. The glycation of proteins, known as the Maillard reaction, is the non-enzymic reaction between a protein and a reducing sugar. The first step of this reaction is the formation of an unstable Schiff base that can rapidly undergo rearrangement to give an Amadori product when derived from glucose, or a Heyns product when derived from fructose. These early glycation products may then undergo various reactions (oxidation, cleavage, dehydration, covalent binding) to form irreversible AGE. It has been shown that an accumulation of AGE appears during ageing in human muscle ${ }^{(31)}$, brain ${ }^{(32)}$ and bones $^{(33)}$. Because it changes protein structure, glycation can lead to modifications of their mechanical properties (collagen, crystalline), of their enzymic activities or of their 
degradability ${ }^{(34)}$, with either an acceleration or an inhibition, leading eventually to an accumulation of the modified protein.

At first, it was thought that fructose was not involved in the glycation process whereas in fact it reacts ten times more rapidly than glucose with $-\mathrm{NH}_{2}$, as has been shown in vitro ${ }^{(35,36)}$ and in Saccharomyces cerevisiae ${ }^{(37)}$. Despite the high hepatic fructose extraction, resulting in low fructosaemia, fructose can also glycate protein through its metabolites and especially oxaldehydes such as glyoxal, methylglyoxal and 3-deoxyglucosone, whose reactivity towards $-\mathrm{NH}_{2}$ is extremely high $^{(38,39)}$. Moreover, HCIAS disturbs glucose tolerance and insulin sensitivity, leading to hyperglycaemia, increasing glucose-derived protein glycation. Thus, long-term fructose consumption (in drinking water) triggers an increase in rat glycated $\mathrm{Hb}^{(40)}$ and in liver carboxymethyl lysine content (even a higher increase than glucose) in mice ${ }^{(41)}$.

This enhanced production of AGE induced by fructose could make an important contribution to the development of metabolic disorders due to HCIAS. Once again, the effect of HCIAS seems similar to the effect of ageing, and HCIAS could simply accelerate the effect of ageing.

Inflammation. Epidemiological studies have repeatedly reported an increase in inflammatory markers such as TNF- $\alpha$, IL-1, IL-6 and C-reactive protein (CRP) in the elderly ${ }^{(42-45)}$. This low-grade and long-term increase was called 'inflamm-aging' by Franceschi ${ }^{(46)}$ and should be distinguished from acute inflammation. Many factors can induce such a persistent inflammation: (1) aberrant production of reactive molecules by senescent leucocytes designed to kill pathogens; (2) accumulation of damaged macromolecules and cells, mimicking bacterial products and activating innate immunity; (3) increased occurrence of danger signals (extracellular ATP, ceramides, amyloid, peroxidised lipids, AGE, extracellular DNA resulting from necrosis or pyroptosis of dying cells, mitochondrial remains sharing similarity with bacterial components like cardiolipins or DNA, etc.) detected by sensors like inflammasome initiating immune reactions; (4) age-related alteration of the capacity of the gut to contain microbes and/or their products; (5) changes from a low-inflammation microbiote to a high-inflammation microbiote with a lower protection from Epstein-Barr virus or cytomegalovirus; (6) accumulation of senescent cells, macrophages, stromal fibroblasts, stem cells, with damaged DNA, able to secrete proinflammatory cytokines, in particular in adipose tissue; and (7) age-related immunosenescence, probably due to life-long exposure to pathogens, with a decline in adaptive immunity, and mild compensating hyperactivity of innate immunity, inappropriate regulation of the complement pathway and thymus involution $^{(47,48)}$. In addition, testosterone and oestrogen decline could partially explain this low-grade inflammation, making the organism more sensitive to stress and thus leading to a chronic activation of macrophages partly regulated by steroid hormones $^{(40,46,49)}$.

However, low-grade inflammation can also derive from other environmental factors, especially factors able to induce oxidative stress. Indeed, production of inflammatory cytokines is dependent on NF- $\mathrm{kB}$ pathway, activated by ROS. Not surprisingly, fructose is one of these environmental factors and was shown to activate NF- $\mathrm{kB}$ and thus induce inflammation in rats ${ }^{(50)}$

Fructose-induced inflammation has been established in rats with an increase in serum, liver and muscle TNF- $\alpha$, IL- 6 and IL-1 $\beta$ concentrations ${ }^{(51-53)}$. In healthy and normal-weight humans: (1) acute intake of $50 \mathrm{~g}$ of fructose induced a $4 \%$ increase in mean CRP plasma content in the following $2 \mathrm{~h}$ after feeding, whereas $50 \mathrm{~g}$ glucose decreased CRP by $5 \%{ }^{(54)}$; and (2) 3 weeks' consumption of 40 or $80 \mathrm{~g} / \mathrm{d}$ of fructose, glucose or sucrose significantly increased fasting CRP plasma content from $206 \mathrm{ng} / \mathrm{ml}$ to $375-430 \mathrm{ng} / \mathrm{ml}$, with no significant differences between sugars, although the highest values were obtained for $80 \mathrm{~g} / \mathrm{d}$ fructose $(430 \mathrm{ng} / \mathrm{ml})$ and $80 \mathrm{~g} / \mathrm{d}$ sucrose $(422 \mathrm{ng} / \mathrm{ml})^{(54,55)}$. Moreover, in middle-aged women, Liu et al. ${ }^{(56)}$ found a positive association between dietary glycaemic load and plasma CRP. Finally, as it will be described below, fructose can increase body adipose tissue mass, and it was shown that adipose tissue can produce pro-inflammatory cytokines not only after macrophage infiltration, but also as a metabolic reaction to food abundance. This phenomenon is called 'metaflammation' and is believed to contribute greatly to 'inflamm-aging, (48)

Thus, HCIAS, like ageing, leads to a vicious circle involving ROS, AGE and pro-inflammatory mediators. Indeed, ROS, by activating the NF- $\kappa \mathrm{B}$ pathway, trigger an inflammatory response, but pro-inflammatory cytokines, especially TNF- $\alpha$, are also able to induce ROS production. Furthermore, formation of AGE can also be promoted by the presence of ROS and be responsible for inflammation through their interaction with their receptor RAGE (receptor for AGE) ${ }^{(57,58)}$. This vicious circle could participate in the development of most of the HCIAS-induced disorders, including the modification of the lipid profile.

It is clear that the low-grade inflammation observed during ageing can have multiple origins, since it is a common denominator of many diseases and aggressions, but HCIAS can clearly contribute to this phenomenon.

Dyslipidaemia. During life, plasma lipid concentrations seem to follow a bell curve. Several authors have observed in humans that plasma total cholesterol, LDL-cholesterol and TAG concentrations increase progressively with age until the age of 50-60 years, whereas HDL-cholesterol decreases or does not vary ${ }^{(59,60)}$. These changes are positively correlated with fat mass and insulin resistance and negatively with physical activity. Then, total cholesterol, LDL-cholesterol and TAG start to decrease while HDL-cholesterol increases ${ }^{(59,60)}$. This evolution could be related to chronic inflammatory diseases, reduction of cholesterol absorption or malnutrition. In addition, Vaarhorst et al. ${ }^{(61)}$ proposed that there was a negative association between TAG levels and longevity, which could bias results of human cross-sectional studies. Thus, a decrease in mean TAG level with age could also be observed in cross-sectional studies due to the over-mortality of individuals with high TAG levels.

This last study suggests that maintaining an optimal lipid profile can be essential for healthy ageing. So, all factors that can increase total cholesterol and/or TAG levels could promote the development of age-related disorders and thus reduce longevity. One of the first dysregulations induced by a 
HCIAS diet is precisely dyslipidaemia, mainly characterised by an increase in TAG levels. Indeed, fructose can induce the hepatic synthesis of TAG in two ways: on one hand, through its hepatic metabolism, it provides pyruvate and dihydroxyacetone phosphate which can be used as substrates for $\mathrm{DNL}^{(6)}$. On the other hand, in the rat, fructose is able to induce transcription factors SREBP-1c and ChREBP that are regulating genes involved in $\mathrm{DNL}^{(10)}$.

In rats and mice, the increase in the plasma level of TAG following a high-sucrose or a high-fructose diet is now well characterised: fasting plasma TAG level was doubled when $10 \%$ fructose was introduced in drinking water ${ }^{(62,63)}$, or was increased in proportion to the duration of the treatment and the amount of fructose when fructose was included in the diet, from $\times 1.5$ to $\times 3.5^{(64-66)}$. This has been confirmed in humans. Healthy men were fed during $42 \mathrm{~d}$ either with glucose ( $14 \%$ energy) or fructose (17\% energy) and fasting plasma TAG was $20 \%$ higher in fructose-fed subjects than in glucose-fed subjects ${ }^{(67)}$. Furthermore, after feeding normal human subjects either with glucose or fructose (30\% energy), over $23 \mathrm{~h}$, the mean area above basal of plasma TAG was multiplied by 6.5 in fructosefed subjects compared with glucose-fed subjects ${ }^{(68)}$.

HCIAS could also increase plasma total cholesterol and LDLcholesterol concentrations in men and animals ${ }^{(62,66,69-71)}$. However, this remains controversial since a study of Lowndes et $a l .{ }^{(72)}$ showed that in overweight or obese individuals fructose consumption at up to the 90th percentile population consumption level did not raise cholesterol concentration.

Besides genetic factors, alteration of plasma lipid content during ageing is more likely to be related to nutrition and fitness status than to intrinsic ageing. Among nutritional factors, HCIAS is thus probably an important factor that could trigger dyslipidaemia during ageing.

Insulin sensitivity and glucose tolerance. Ageing is often accompanied by the development of insulin resistance. The first steps of this insulin resistance are characterised by a higher increase of fasting blood insulin to maintain a normal blood glucose level. This decrease in insulin efficiency occurs despite a normal insulin binding to its receptor ${ }^{(73,74)}$, implying a defect of insulin signalling downstream of insulin binding. Indeed, after efficient binding to its receptor, in elderly subjects, insulin generates a lower stimulation of insulin receptor substrate (IRS)-1 phosphorylation and thus of insulin signalling than in young adult subjects ${ }^{(75)}$. Moreover, a decrease in the concentration of the insulin-stimulated GLUT, GLUT-4, could also be implicated in insulin resistance since muscle GLUT4 concentration is negatively associated with age in men and women ${ }^{(76)}$. This age-related alteration in insulin sensitivity seems not due to intrinsic ageing but rather to a decrease in physical activity or to modification of body composition (especially a rise in fat mass which contributes to the age-associated lipotoxicity), events that are often observed during ageing in rats and human subjects $^{(77-79)}$. However, ageing could also contribute to glucose metabolism disorders through a decrease in secretory capacity of $\beta$-cells in response to glucose as was shown in humans ${ }^{(80-82)}$. All of these dysregulations may lead to type 2 diabetes, and it is well established that type 2 diabetes prevalence increases with age.
Due to its metabolism, independent from insulin (fructose ingestion does not induce insulin secretion) and thus to its low glycaemic index, fructose has been considered for a long time as a good sugar source, especially for diabetic subjects. Now, several studies rather highlight its deleterious effects on insulin sensitivity.

As early as 1964, Cohen \& Teiltelbaum showed that replacing starch by sucrose in rat diet (67\% of total energy) led to glucose intolerance. This glucose intolerance develops all the more sooner when the percentage of sucrose in the rat diet is high $^{(83)}$. They also showed that this condition was reversible (if rats are reversed back to the starch diet). In men, the consequences of HCIAS are more controversial and variable ${ }^{(84)}$. In healthy men, Faeh et $a l .{ }^{(85)}$ showed that the consumption of a diet containing $25 \%$ of total energy as fructose led to insulin resistance after only $6 \mathrm{~d}$, whereas Black et $a l^{(86)}$ revealed no difference in insulin sensitivity after 6 weeks' consumption of a diet containing 10 or $25 \%$ of total energy as sucrose. This difference between the effects of fructose and sucrose is in favour of a responsibility of fructose (rather than glucose) in the deleterious effects of added sugar. Several studies have been conducted aiming to compare the effects of glucose and fructose on carbohydrate homeostasis and confirm this hypothesis. Among those, Thorburn et al. ${ }^{(87)}$ reported an impairment of insulin sensitivity in fructose-fed rats but not in glucose-fed rats when both carbohydrates provided $33 \%$ of total energy. Similar results have been observed in $\operatorname{dogs}^{(88,89)}$ and men ${ }^{(90,91)}$.

During a high-sucrose or high-fructose diet in the rat, insulin resistance occurs first in the liver with a decrease in the insulininduced inhibition of glucose liver production ${ }^{(92,93)}$. Then, insulin resistance extends to peripheral tissues with a decrease in insulininduced glucose uptake by adipose tissues and lastly by mus$\mathrm{cle}^{(94-97)}$. This impairment is first reflected by an increase in fasting and postprandial blood insulin. Indeed, in rats, 9 weeks of a $60 \%$ fructose diet induced an increase in fasting blood insulin whereas fasting glycaemia was unchanged ${ }^{(98)}$. These results are in line with the increase in insulin secretion by pancreatic $\beta$-cells observed by Khanal et al. ${ }^{(99)}$ after 8 weeks of a high-fructose diet. This suggests that during the first steps of insulin resistance development, the amount of insulin needed to regulate ingested and produced glucose increases but that the increase in insulin production is sufficient to maintain normal glycaemia. However, when the duration of overconsumption is prolonged (variable depending on the studies), a true resistance to insulin action appears. After 7 weeks, glycaemia following glucose ingestion increases more in mice fed a diet containing $40 \%$ sucrose than in mice fed a control diet ${ }^{(70)}$. In obese and overweight subjects, the consumption of fructose-sweetened beverages providing $25 \%$ of energy requirements for 10 weeks induced a significant increase in fasting blood glucose, contrary to glucose-sweetened beverages $^{(90)}$.

Insulin resistance due to HCIAS seems to affect primarily carbohydrate metabolism since insulin still induces DNL stimulation in mice ${ }^{(100)}$, which may also explain the implication of fructose in fatty liver development. Moreover, as shown in human studies, fat accumulation in liver and in muscle could contribute to insulin resistance, creating a vicious circle $^{(101,102)}$. Mechanisms involved in this vicious circle have been well 
described in a review by Morino et al. ${ }^{(103)}$. Briefly, the increase in diacylglycerol disturbs kinase activity of IR and thus reduces phosphorylation of IRS-1 and IRS-2, leading to an inhibition of insulin signalling, especially of the PI3K/Akt pathway. In liver, it leads primarily to a reduction in glycogen synthesis and in gluconeogenesis inhibition. In muscle, it induces a lower activation of GLUT4 translocation, and consequently of insulininduced glucose uptake. However, ectopic fat deposition alone does not explain insulino-resistance since it has been shown that hepatic steatosis can occur independently of insulin sensitivity alteration ${ }^{(104,105)}$. Thus, other factors can be involved in insulin resistance appearance.

Indeed, AGE could also regulate IRS-1 phosphorylation as shown in insulin-treated Hep3B cells ${ }^{(106)}$. Through c-Jun N-terminal kinase (JNK) activation, AGE induce the phosphorylation of IRS-1 serine 307 residue. This $\operatorname{ser}^{307}$ phosphorylation inhibits insulin-induced tyrosine phosphorylation of IRS-1 but also the interaction between IR and IRS-1, consequently inhibiting insulin signalling ${ }^{(107,108)}$. JNK can also be activated by $\operatorname{ROS}^{(26)}$ and TNF- $\alpha^{(109)}$. So, JNK could play a major role in added sugar-induced insulin resistance development as confirmed by Wei \& Pagliassotti ${ }^{(110)}$

Besides deregulating IR activity, HCIAS also leads to a decrease in IR number in rat skeletal muscle and liver, thus contributing to insulin resistance ${ }^{(64)}$. Finally, the fructose-induced rise in uric acid levels associated with HCIAS has also been identified as a factor potentially responsible for decreased insulin sensitivity using an acute hyperuricaemia mouse model ${ }^{(111)}$.

Thus, insulin resistance appears as a major metabolic disorder which occurs both during ageing and HCIAS. Disruption of insulin signalling seems to play a key role in both cases, even if some mechanisms may differ. For instance, $\beta$-cell function seems to be altered during ageing but not after HCIAS. Other mechanisms are similar with alteration of insulin signalling in relation to oxidative stress, glycation and inflammation. Thus, although there is a lack of data in the literature exploring the cumulative effects of ageing and HCIAS, we can speculate that HCIAS could not only accelerate the age-related deterioration of insulin resistance but a cumulative effect of ageing and HCIAS seems also possible due to the deterioration of $\beta$-cell function, which seems more specific of the ageing process.

\section{Secondary diseases}

Other metabolic alterations are observed both during ageing and during HCIAS, but these more complex alterations always involve either oxidative stress, protein glycation, inflammation, dyslipidaemia, or insulin resistance and thus can be considered as secondary to these primary alterations.

Non-alcoholic fatty liver disease. Age is a risk factor for many metabolic diseases, including liver diseases. Non-alcoholic fatty liver disease (NAFLD) is characterised by the accumulation of lipids in hepatocytes, and constitutes the most common chronic liver disease ${ }^{(112)}$. In case of cell lesions and inflammation it can evolve into non-alcoholic steatohepatitis, increasing the risk of cirrhosis, fibrosis or hepatocellular carcinoma. TAG accumulation in liver is the result of an imbalance in hepatic lipid metabolism, reflecting the fact that lipid uptake or synthesis is higher than its removal. Liver fatty acids may come from dietary intake, DNL or from lipolysis. Removal of liver lipids can be provided by $\beta$-oxidation, fatty acid re-esterification, or export as VLDL-TAG. Epidemiological studies show that in men, the prevalence of NAFLD increases from young to middle age, and declines after the age of 50 or 60 years, whereas women are protected by oestrogens, and the prevalence increases after menopause but declines after the age of 70 years ${ }^{(113)}$. Genetic or environmental factors (such as HCIAS) could lead to an earlier appearance of NAFLD. The appearance of NAFLD seems then more related to environmental factors than to intrinsic ageing, but the capacity to cope with the disease decreases with age ${ }^{(113)}$.

Indeed, as previously described, fructose is able to disturb fatty acid metabolism, promoting NAFLD development, even in young individuals ${ }^{(114)}$. HCIAS is recognised as an important risk factor for NAFLD development ${ }^{(115-117)}$. By stimulating DNL, fructose induces in humans an accumulation of ectopic lipids, mainly in the liver, but also in muscle ${ }^{(69,118)}$. Ishimoto et al. ${ }^{(119)}$ demonstrated the key role of fructose using fructokinase knockout mice: these knock-out animals were protected from steatohepatitis induced by a high-fat/high-sugar diet as opposed to wild-type mice. Thus, if animals cannot metabolise fructose in liver, they do not develop steatohepatitis. In addition, the action of fructokinase can be amplified by uric acid produced during liver fructose metabolism. Indeed, as studied in isolated hepatocytes and in rats, through ChREBP activation, uric acid can induce fructokinase activation, essential to direct fructose to $\mathrm{DNL}^{(120,121)}$

AGE could also mediate the involvement of fructose in NAFLD since, according to results obtained in obese patients, carboxymethyl-lysine (CML) accumulation was significantly correlated with the grade of hepatic steatosis ${ }^{(58)}$. Furthermore, in rats, dietary AGE exacerbate NAFLD via the generation of oxidative stress $^{(122)}$. Their action could involve the stimulation of lipogenesis by SREBP-1c as suggested by Mastrocola et $a l .{ }^{(41,123)}$; they showed in mice that fructose-induced CML accumulation could interact with the SREBP-cleavage activating protein (SCAP) leading to a prolonged activation of SREBP-1 ${ }^{(41)}$. The same phenomenon, also in mice, is observed in muscle and could participate in intramuscular fat deposition $^{(123)}$.

The relationship between HCIAS-induced insulin resistance and NAFLD has also been studied but this relationship is still poorly understood. Indeed, some authors have suggested that hyperinsulinaemia disturbs fatty acid storage in adipose tissue and promotes fatty acid deposition in liver ${ }^{(124)}$, while others have suggested that it is the appearance of ectopic lipids that causes insulin resistance development, at least in the rat ${ }^{(125)}$. Other authors think that NAFLD and insulin resistance are not always associated ${ }^{(105,126)}$. Moreover, the presence of hypertension in addition to insulin resistance could also favour liver disease in rats ${ }^{(127)}$.

However, it is clear that HCIAS plays a major role in NAFLD induction, essentially through DNL. During ageing, the risk of NAFLD development increases after 40-50 years old, but, once 
again, it seems more related to environmental factors than to intrinsic ageing.

Hypertension. Hypertension is frequent in the general population, and most of the time it cannot be related to a specific disease. Risk factors generally recognised are overweight, lack of exercise, high salt intake, low $\mathrm{K}$ intake and alcohol. But the main risk factor is clearly ageing. Hypertension prevalence increases with age and according to the Framingham Heart Study, $90 \%$ of individuals with normal blood pressure at the age of 55 years will develop high blood pressure over the course of his/her remaining life-time and about two-thirds of males and three-quarters of females develop hypertension by 70 years of age ${ }^{(128)}$. This age-related hypertension has several causes, and they seem to derive mostly from chronic inflammation, oxidative stress and subsequent alterations in endothelial functions ${ }^{(129)}$. In particular, an increase in aortic stiffness is observed during ageing in humans ${ }^{(130)}$. Collagen and elastin stiffness is highly increased by their glycation ${ }^{(131)}$ and thus AGE could be involved in age-related endothelial dysfunction. Moreover, AGE, in vivo in animals and in humans, or in vitro, are also able to inhibit NO synthesis by endothelial NO synthase (eNOS) $)^{(132-135)}$.

Regarding the effect of HCIAS, considering the ability of fructose to glycate proteins or to increase glycaemia and thus glycation through the development of insulin resistance, it logically appears as a risk factor for hypertension. Indeed, prohypertensive effects of fructose have been described in animals. In rat studies, high amounts of fructose in the diet (more than $60 \%$ of fructose either in mass or in energy) were used and systolic blood pressure measured by plethysmography (tail-cuff method) was found to be significantly increased (+17 to $23 \%$ ) after 2 to 8 weeks $^{(136,137)}$. Two longer-term studies ( 9 or 12 months of supplementation), using the same method, confirmed that overall fructose significantly increased systolic blood pressure but that the difference between fructose-fed and starch-fed rats attenuated at the end of the study ${ }^{(138,139)}$. However, one study casted some doubts on the results obtained by all these studies by showing that the response of arterial blood pressure to fructose measured by telemetry transmitters did not agree with measurements made by plethysmography ${ }^{(137)}$. However, one study performed in dogs and using another method to measure blood pressure confirmed that a highfructose diet increased blood pressure ${ }^{(88)}$. Finally, in human subjects, an epidemiological study also confirmed that consuming a higher than average amount of fructose increased the risk of developing hypertension ${ }^{(140)}$. In addition to AGE, other mechanisms could explain the impact of HCIAS on blood pressure as salt retention, a major contributor to hypertension development. Indeed, through GLUT5, fructose is able to stimulate the expression of gut and kidney salt transporters and thus to increase its absorption. Besides, an increase in fructose intake leads to a decreased urinary salt excretion ${ }^{(141)}$. Insulin resistance could also contribute to high blood pressure and several studies in rats and human subjects suggest that the improvement in insulin sensitivity is able to prevent hypertension appearance ${ }^{(142-145)}$. Long-term hyperinsulinaemia seems to induce a prolonged activation of the sympathetic nervous system leading to an increased production of catecholamine and vasoconstrictors such as endothelin I, angiotensin II and thromboxane A2, as well as a decreased production of vasodilators such as NO and prostacyclin 2, all of which lead to an impairment of endothelial function and therefore to hypertension ${ }^{(146)}$. Furthermore, as shown in humans, the rise in serum uric acid levels could also be involved in hypertension development ${ }^{(147-149)}$, partly by inhibiting NO action in a rat model ${ }^{(150)}$ or through insulin resistance, as previously described (see above). The causal role of uric acid in fructose-induced hypertension was highlighted by Nakagawa et $a l .^{(151)}$ : in rats fed a high-fructose diet, use of a pharmacological inhibitor of uric acid production was able to prevent or reverse the fructoseinduced increase in blood pressure.

Finally, given the results of experimental studies and the numerous possible mechanisms proposed, it seems likely that HCIAS could be added to the list of risk factors that can lead, perhaps in combination with other recognised risk factors, to the marked increase in the prevalence of hypertension that is observed during ageing.

Central nervous system disorders. The central nervous system is highly sensitive to ageing effects, leading progressively to cognitive function impairment. Cognitive decline has several manifestations, such as impairment of attention, speed of information integration, language, executive functions; however, the main cerebral function affected by ageing is memory ${ }^{(152)}$. Also, central nervous system ageing, by affecting motor neurons, also participates in the alteration of muscle functional capacity ${ }^{(153)}$.

Several structural and functional modifications can explain age-related changes, especially the decline in grey matter volume which begins after the age of 20 years. It is partly explained by the decrease in neuron size, synaptic density, but also of neuron number ${ }^{(154)}$. Neuronal death could be induced by peptide $\beta$-amyloid (A $\beta$ ) aggregation ${ }^{(155,156)}$. $\beta$-Amyloid peptide is the product of $\beta$-amyloid precursor protein (APP) cleavage by secretases. When $A \beta$ is not degraded or is overproduced, it polymerises in soluble oligomers and aggregates, ultimately leading to plaque formation. Soluble oligomers are probably responsible for neurotoxic effects of $\mathrm{A} \beta$, through several mechanisms such as membrane disruption, synaptic transmission impairment and mitochondrial dysfunction ${ }^{(157)}$.

White matter integrity could also be affected during ageing, which also correlates with cognitive performance ${ }^{(158,159)}$.

Even if these alterations leading to cognitive decline occur during normal ageing, one may wonder whether environmental factors could also play a role. There is a growing interest in the study of the association between sugar consumption and cognition. An epidemiological study showed that HCIAS was associated with lower cognitive function in non-diabetic subjects aged 45 to 75 years $^{(160)}$. This association was also established in rodents. A study conducted in rats by Ross et al. ${ }^{(161)}$ showed that intake of a $60 \%$ fructose diet for 19 weeks induced an impairment of spatial memory. In mice, consumption of water supplemented with $15 \%$ fructose for 8 weeks also led to spatial memory impairment and affected neuronal and synaptic plasticity ${ }^{(162)}$. Similarly, young rats drinking a $32 \%$ sucrose solution, after 6 and 
8 weeks, had a deficit in an object recognition task and in spatial learning and memory ${ }^{(163,164)}$. Recently, systems nutrigenomics was used to assess the effect of 6 weeks of $15 \%$ fructose in drinking water on transcriptome and epigenome sequencing in rat hypothalamus (metabolic control) and hippocampus (cognitive processing $)^{(165)}$. The model induced metabolic alterations (dyslipidaemia and insulin resistance) and impaired memory, and was associated with very significant reprogramming of DNA methylation, transcript abundance, alternate splicing, and gene networks governing cell metabolism, cell communication, inflammation, and neuronal signalling. Interestingly, DHA supplementation could largely reverse fructose-induced genomic and network modifications ${ }^{(165)}$.

Many studies have highlighted an association between insulin sensitivity and cognitive function. Fructose-induced insulin resistance is well known in liver, muscle and adipose tissue, but it could also occur in the central nervous system. Indeed, in fructose-fed hamsters ( $60 \%$ of energy), in response to insulin, the tyrosine phosphorylation levels of the neural IR and IRS-1, as well as phosphorylation of threonine 308 and serine 473 (residues necessary for Akt activation), were reduced ${ }^{(166)}$. In rats, fructoseinduced insulin resistance was correlated with memory deficiency, measured by latency time in the Barnes maze test, suggesting that insulin resistance may be involved in the alteration of cognitive functions ${ }^{(167)}$. Several mechanisms linking impairment of insulin signalling in the brain and neurodegenerative diseases are possible and one of them is the inhibition of Akt kinase, leading to dephosphorylation of glycogen synthase

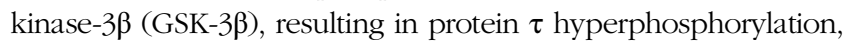
a hallmark of neurodegenerative diseases ${ }^{(168,169)}$. Another possibility is that hyperinsulinaemia could induce $A \beta$ accumulation through a direct competition between $\mathrm{A} \beta$ and insulin for the insulin-degrading enzyme ${ }^{(170)}$. These results are in line with the increase of $\mathrm{A} \beta$ amount found in the cerebral cortex and hippocampus of high-sucrose-fed mice ${ }^{(171)}$. Other factors could still be

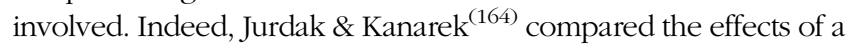
high-fat diet with the effect of a high-sucrose diet on cognitive functions. Although both diets altered fasting blood level, suggesting insulin resistance, only the sucrose diet reduced the performance of animals for an object recognition task.

In particular, as shown by Meng et al. ${ }^{(165)}$, inflammation could mediate the damaging effects of fructose on cognition since inflammation is also increased in the brain following a HCIAS. Adolescent rats given a high-fructose maize syrup solution for $30 \mathrm{~d}$ developed neuro-inflammation with an increase in IL-6 and IL-1 $\beta$ protein levels in the hippocampus ${ }^{(172)}$. Moreover, neuroinflammation, especially hippocampal expression of TNF- $\alpha$, was correlated with lower scores on the final place task in rats ${ }^{(173)}$. Rats fed a 35\% fructose solution over 8 weeks had more TNF- $\alpha$ in the brain and an impaired memory, and cholecalciferol supplementation prevented these effects ${ }^{(174)}$. More generally, many studies in human subjects highlighted an association between inflammation and cognitive decline, and showed that pro-inflammatory protein levels, such as CRP, IL-1 $\beta$ and IL- 6 are inversely correlated with cognitive capacity ${ }^{(175-178)}$. It is also proposed that increased insulin resistance (as can be induced by HCIAS, and more generally during the metabolic syndrome) can trigger peripheral and central nervous system inflammation, which induces neurotoxicity ${ }^{(174,179)}$. In addition, a vicious cycle could exist during the metabolic syndrome: inflammation induced by the metabolic syndrome could alter the hypothalamus, a major area in the central nervous system for integrating nutritionally relevant information coming from the peripheral organs, which could in turn alter neuropeptide transmission and thus accelerate obesity $^{(180)}$. It has been shown that rats receiving $300 \mathrm{ml} / \mathrm{d}$ of $10 \%$ fructose drinking water for 8 weeks suffered hypothalamic astrocytosis (alteration of astrocytes, the cells that support and protect neurons) and inflammation through induction of the tolllike receptor 4 (TLR4)/NF- $\mathrm{BB}$ pathway and HDAC3-induced production of proinflammatory mediators ${ }^{(181)}$. There is thus a close link between insulin resistance and inflammation in the brain.

In addition, level of ROS has also been associated with the development of neurodegenerative diseases. The brain is particularly sensitive to oxidative damage because of its low antioxidant defences and its high oxygen consumption. Oxidative stress promotes aggregation of misfolded protein such as $\tau$ protein and $\mathrm{A} \beta$, involved in Alzheimer's disease and $\alpha$-synuclein and mutant huntingtin protein involved, respectively, in Parkinson's and Huntington's diseases ${ }^{(182)}$. One of the potential underlying mechanism, studied in vitro, is the activation of JNK and p38 kinases by ROS, leading to activation of the enzyme responsible for APP cleavage and to $\tau$ protein phosphorylation $^{(183,184)}$. AGE could also be implicated in the activation of the JNK pathway and thereby be a link between sugar consumption and neurodegenerative diseases. Also, neuronal accumulation of AGE has been found in senile plaques and neurofibrillary tangles of Alzheimer's patients ${ }^{(185)}$ and in Lewy's body of Parkinson's patients ${ }^{(186)}$. Moreover, some proteins implied in neurodegenerative diseases can directly undergo the glycation reaction, which promotes their aggregation; this is the case for $\mathrm{A} \beta, \tau$ protein and $\alpha$-synuclein as studied post-mortem or in vitro ${ }^{(187-189)}$. AGE, when added in vitro in neuroblastoma cells or injected in vivo in mice, could also raise $A \beta$ level by inducing the expression of precursor protein $\mathrm{APP}^{(190)}$.

Thus, several deregulations induced by HCIAS also occur in the brain, where they could contribute to age-related alteration of cognitive functions, especially by promoting aggregation of misfolded protein involved in neurodegenerative diseases.

Sarcopenia. Muscle is particularly affected during ageing with a progressive loss of muscle mass and function from the age of 50 years, called sarcopenia. With a loss of $1-2 \%$ per year, total muscle mass loss reaches up to $30 \%$ at the age of 70 years, while muscle function loss is about 3\% per year after age 60 years ${ }^{(191)}$. Although highly dependent on the diagnostic tools used, sarcopenia prevalence seems to range from 8.4 to $27 \cdot 6 \%{ }^{(192)}$. The origin of sarcopenia is multifactorial (exercise, hormonal changes) but it is partially explained by a decreased ability of aged muscle to respond to the anabolic effect of a meal ${ }^{(193)}$.

Indeed, after a meal, muscle protein synthesis is stimulated, and muscle protein degradation is inhibited, resulting in protein accumulation in muscle. On the contrary, in the post-absorptive state, protein synthesis decreases, and protein degradation increases, resulting in net protein loss. In young growing 
individuals, fed-state anabolism exceeds postprandial catabolism, whereas in adults, there is equilibrium between fed-state anabolism and post-absorptive losses. During ageing, it was shown both in rats and men that fed-state anabolism is less efficient, which could explain a slow erosion of muscle during ageing, and also a decrease in the capacity to recover after an acute catabolic period ${ }^{(194,195)}$.

The effect of a meal on muscle anabolism is essentially dependent on the actions of insulin and amino acids. Amino acids are the substrates of protein synthesis, but some of them like leucine have also signalling effects and can stimulate protein synthesis. It has been clearly shown, both in animals and human subjects, that muscle protein synthesis is less sensitive to the stimulating effect of amino acids/leucine during ageing, and that more amino acids/leucine are necessary to obtain a normal stimulation of muscle protein synthesis ${ }^{(196,197)}$. Insulin inhibits muscle protein degradation and, at normal physiological concentrations, has a permissive effect on the stimulation of protein synthesis by amino acids. In addition, insulin allows an increase in muscle blood flow ${ }^{(198)}$, which is reduced in elderly subjects ${ }^{(199)}$. As a matter of fact, insulin resistance is associated with lean mass loss in old men ${ }^{(200)}$; moreover, in aged diabetic patients, lean mass loss can be attenuated by insulin sensitisers ${ }^{(201)}$.

In parallel, the effect of oxidative stress and inflammation on muscle anabolism has also been tested during ageing. It has been shown that oxidative stress could contribute to anabolic resistance since an antioxidant supplementation can restore the stimulation of protein synthesis by leucine in old rats ${ }^{(202)}$. Similarly, inflammation is associated with impaired postprandial protein synthesis in muscle of old rats. Indeed, based on a plasma marker of inflammation, muscle protein anabolism response to feeding was normal in non-inflamed old rats, and reduced in low-grade-inflamed rats ${ }^{(203)}$. In addition, treatment of old rats with a non-steroidal antiinflammatory drug (ibuprofen) was able to restore the blunted muscle anabolic response to feeding and improve muscle mass ${ }^{(204)}$.

Given the basic alterations induced by HCIAS (see above), it seemed possible that it could also accelerate sarcopenia. Indeed, we showed that after 5 months of a high-sucrose diet in old rats, sucrose-fed rats lost significantly more lean body mass than starch-fed rats $(-8.1 \quad v .-5.4 \%$, respectively) and final muscle mass was $11 \%$ higher in starch- than in sucrose-fed rats $^{(205)}$. Accordingly, meal-induced stimulation of muscle protein synthesis was significantly lower in sucrose- $(+7 \cdot 3 \%)$ than in starch-fed rats $(+22 \%)$. We detected little difference in inflammation and oxidative stress between starch-fed and sucrose-fed rats, but insulin sensitivity index was divided by 2 , suggesting that it was through a modification of insulin action that sucrose altered muscle anabolism and accelerated sarcopenia. Yet, so far, only a few authors have studied the impact of sugar consumption on muscle and even less in the elderly. Results obtained from an in vitro study showed that fructoseinduced oxidative stress accelerates the rate of apoptosis in L6 myotubes through mitochondrial dysfunction ${ }^{(206)}$ and thus could also modify degradation rates to promote muscle mass loss. These results are in line with one study conducted in growing rats which showed that gastrocnemius mass was lower in high-sucrose-fed rats that in control rats ${ }^{(207)}$.

Finally, given the multifactorial origin of sarcopenia, it seems clear that it will occur even in healthy subjects consuming no added sugars, but it seems likely that HCIAS can accelerate sarcopenia.

Osteoporosis. Bone health is progressively altered during ageing through osteoporosis ${ }^{(208)}$. In the USA, about 10 million individuals over the age of 50 years have osteoporosis of the hip ${ }^{(209)}$. Cytokines seem to be involved in bone loss ${ }^{(210)}$. Indeed, pro-inflammatory cytokines such as TNF- $\alpha$ and IL- 1 are able to stimulate osteoclast lifespan and activity, while inhibiting osteoblast function ${ }^{(211)}$. Hence, as showed by several epidemiological studies, higher levels of inflammatory markers are associated with lower bone mineral density and higher risk for fracture ${ }^{(212-214)}$. Oxidative stress also promotes osteoporosis development by inhibiting osteoblast differentiation and enhancing osteoclastogenesis ${ }^{(215)}$ and has been associated with lower bone mineral density and increased risk of fracture in postmenopausal women ${ }^{(216,217)}$.

Accordingly, fructose, as a pro-oxidant and pro-inflammatory factor, could be expected to favour bone loss. However, only a few studies have been interested in the effect of fructose on osteoporosis. It is difficult to study in rodents because these animals are not prone to osteoporosis. It has been shown that fructose could accelerate osteoporosis in rats with ovariectomy, probably through insulin resistance ${ }^{(218)}$. Also, Felice et al. ${ }^{(219)}$ showed that HCIAS impaired bone regeneration after parietal wounds in rats and affected femoral metaphysis microarchitecture by decreasing the osteogenic potential of marrow stromal cells. However, in young growing rats, high fructose feeding was found to allow a better bone quality and strength than high glucose feeding ${ }^{(220)}$. Also, 15 weeks of $10 \%$ fructose in drinking water minimally affected bone structure in mice whereas high-fat feeding induced lower trabecular bone volume fraction and thinner cortices in the femur than controls $^{(221)}$. So, the effect of HCIAS on bone health during ageing remains to be clarified.

\section{Body composition and weight, and satiety}

The scope of the present review was to describe the effects of HCIAS, and to compare with the effects of ageing. We showed that fructose consumption has many deleterious effects, in particular when energy intake is high. However, given the specificities of fructose metabolism, when total energy intake is normal or too low, and/or when the amount of ingested fructose is normal, it could have a positive action. For instance, during starvation, fructose could be interesting to spare body proteins: it was shown that fructose infusion during $10 \mathrm{~d}$ fasting in human subjects reduced excretion of total $\mathrm{N}$ by $40 \%$ and seemed to abolish the entire hormone-substrate response to fasting ${ }^{(222)}$. The specificity of fructose metabolism is also involved in the specific and complex issue of the control of body weight, and on the regulation of satiety. Body composition and weight undergo changes over the years. Body weight increases until about 60 years old and then gradually decreases ${ }^{(223,224)}$. This is explained by an increase in 
fat mass until the age of $70-75$ years which then stabilises whereas lean body mass steadily decreases with ageing from the age of 50 years ${ }^{(225-227)}$. Some authors have even observed a decrease in fat mass from the age of 60 years, which would be in line with the evolution of plasma lipids ${ }^{(22)}$.

A little over a decade ago, Bray et al. ${ }^{(229)}$ highlighted a chronological correspondence between the increase in obesity prevalence and fructose consumption, which has led many authors to consider fructose as a cause of obesity. However, fructose seems to be able to induce metabolic disorders related to obesity, but weight gain is more probably due to energy excess rather than to fructose itself. Indeed, fructose is mostly provided by sweetened beverages and therefore is a part of extra energy that is consumed during obesity. It is well established that the consumption of sugar-sweetened beverages is associated with an increase in $\mathrm{BMI}^{(230,231)}$. By contrast, studies conducted in men with a moderate consumption of fructose (as pure fructose or sucrose) showed no effect on body weight ${ }^{(232,233)}$. Similarly, in animals, when fructose replaces another source of carbohydrates, most studies did not show an effect on weight gain ${ }^{(234,235)}$.

However, fructose could encourage the consumption of extra energy, due to its low satiating effect. Indeed, ingestion of fructose does not induce secretion of the anorexigenic hormone insulin. Furthermore, compared with glucose, fructose induces a lower secretion of leptin (anorexigenic) and a higher level of ghrelin (orexigenic) either in the fasting state in rats or through a lower inhibition of ghrelin secretion than glucose in the postprandial state in women ${ }^{(91,236)}$ and it could lead to leptin resistance as studied in the rat ${ }^{(235)}$. These effects are amplified by the fact that the secretion of neuropeptide Y (NPY) and agouti-related protein (AgRP), two orexigenic neuropeptides synthesised in the hypothalamus, is activated by ghrelin and inhibited by leptin ${ }^{(237)}$. Fructose could also regulate the activity of NPY/AgRP neurons via a decrease in malonyl-CoA concentration: malonyl-COA is able to suppress expression of NPY and AgRP, and to increase the expression of the anorexigenic neuropeptides $\alpha$-melanocyte-stimulating hormone, proopiomelanocortin and cocaine- and amphetamine-regulated transcript ${ }^{(238,239)}$. Contrary to glucose, centrally administered fructose in food-deprived mice leads to an increase in food intake ${ }^{(240)}$. In men, MRI showed that, contrary to glucose, fructose ingestion was not able to reduce the activation of brain regions that regulate appetite (hypothalamus, insula and striatum) and thereby to induce satiety ${ }^{(241)}$.

Thus, it seems clear that consuming a high amount of fructose increases the risk of consuming more energy than necessary, but it is only in that case that body weight is increased. However, as shown previously, HCIAS can accelerate the loss of lean body mass, and can promote fat accumulation ${ }^{(72)}$. Thus, body weight could be unchanged after HCIAS, but with a lower lean body mass, and a higher fat mass as is often observed during ageing.

\section{Conclusion}

HCIAS induces oxidative stress, protein glycation, inflammation, dyslipidaemia and insulin resistance. All these metabolic alterations are closely related to each other and are also observed during ageing. It seems that many of the more

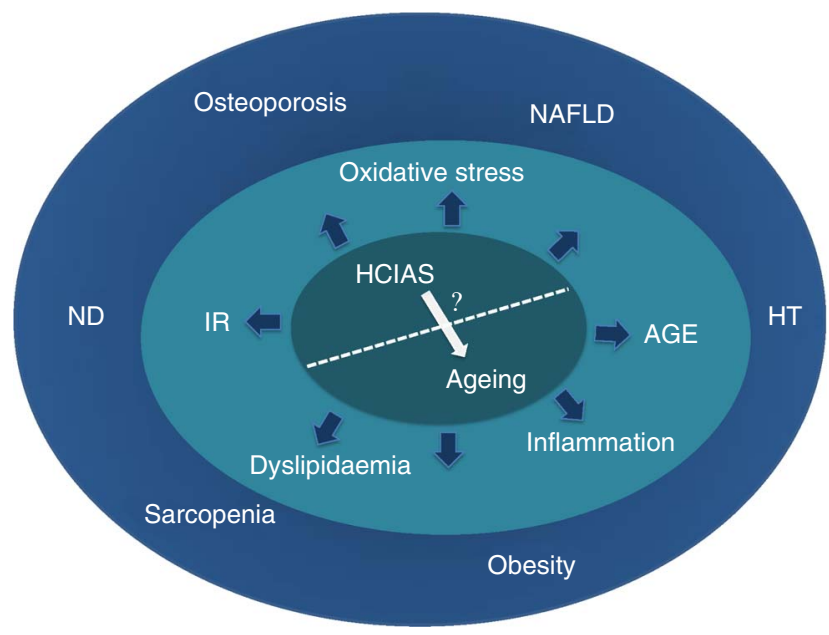

Fig. 2. Effects of high chronic intake of added sugars (HCIAS) and ageing similarities and interactions. Inner circle: HCIAS and ageing both lead to diverse metabolic alterations. HCIAS could accelerate the effect of ageing. Middle circle: primary alterations observed during ageing and HCIAS. Outer circle: these more complex diseases involve alterations listed in the middle circle. NAFLD, nonalcoholic fatty liver diseases; ND, neurodegenerative diseases; IR, insulin resistance; AGE, advanced glycation endproducts; HT, hypertension.

complex alterations that are observed both during ageing and after a HCIAS can derive from these primary alterations, such as NAFLD, hypertension, central nervous system disorders, sarcopenia and osteoporosis (Fig. 2). Ageing is the result of the interaction between genetically programmed phenomena and failure to resist the aggression of our environment. It is clear that HCIAS interferes with the ageing process, accelerates the accumulation of metabolic alterations, although it is not solely responsible for multifactorial metabolic alterations like hypertension or sarcopenia.

Like obesity, HCIAS is probably one of the factors that could prevent the continuous increase in life span that has so far been observed in humans. Such a result was obtained in rats, comparing the longevity of ad libitum starch-fed and fructose-fed rodents ${ }^{(242)}$ especially in female animals, at a dose comparable with human consumption ${ }^{(243)}$. Human-relevant levels of added sugar consumption increase female mortality and lower male fitness in mice ${ }^{(243)}$. Thus, it is clear that, whatever the age, HCIAS should be avoided.

\section{Acknowledgements}

This research received no specific grant from any funding agency, commercial or not-for-profit sectors.

L. M. and E. G. wrote the paper. L. M. has primary responsibility for final content. S. P. and D. D. helped to evaluate and edit the paper.

There are no conflicts of interest.

\section{References}

1. United Nations World Population Ageing (2013) UN World Population Ageing. http://www.un.org/en/development/ desa/population/publications/pdf/ageing/WorldPopulation Ageing2013.pdf (accessed May 2016). 
2. NCD Risk Factor Collaboration (NCD-Risc) (2016) Trends in adult body-mass index in 200 countries from 1975 to 2014: a pooled analysis of 1698 population-based measurement studies with $19 \cdot 2$ million participants. Lancet 387, 1377-1396.

3. López-Otín C, Blasco MA, Partridge L, et al. (2013) The hallmarks of aging. Cell 153, 1194-1217.

4. Crimmins EM, Preston SH \& Cohen B (2011) Explaining Divergent Levels of Longevity in High-Income Countries. Washington, DC: National Academies Press.

5. Lustig RH (2013) Fructose: it's "alcohol without the buzz". Adv Nutr 4, 226-235.

6. Mayes PA (1993) Intermediary metabolism of fructose. $A m J$ Clin Nutr 58, 754S-765S.

7. Johnson RJ, Perez-Pozo SE, Sautin YY, et al. (2009) Hypothesis: could excessive fructose intake and uric acid cause type 2 diabetes? Endocr Rev 30, 96-116.

8. Koo H-Y, Wallig MA, Chung BH, et al. (2008) Dietary fructose induces a wide range of genes with distinct shift in carbohydrate and lipid metabolism in fed and fasted rat liver. Biochim Biophys Acta 1782, 341-348.

9. Coleman RA \& Lee DP (2004) Enzymes of triacylglycerol synthesis and their regulation. Prog Lipid Res 43, 134-176.

10. Koo H-Y, Miyashita M, Cho BH, et al. (2009) Replacing dietary glucose with fructose increases ChREBP activity and SREBP-1 protein in rat liver nucleus. Biochem Biophys Res Commun 390, 285-289.

11. Tappy L \& Lê K-A (2010) Metabolic effects of fructose and the worldwide increase in obesity. Physiol Rev 90, 23-46.

12. Capel F, Buffière C, Patureau Mirand P, et al. (2004) Differential variation of mitochondrial $\mathrm{H}_{2} \mathrm{O}_{2}$ release during aging in oxidative and glycolytic muscles in rats. Mech Ageing Dev 125, 367-373.

13. Hagen TM, Yowe DL, Bartholomew JC, et al. (1997) Mitochondrial decay in hepatocytes from old rats: membrane potential declines, heterogeneity and oxidants increase. Proc Natl Acad Sci U S A 94, 3064-3069.

14. Kuka S, Tatarkova Z, Racay P, et al. (2013) Effect of aging on formation of reactive oxygen species by mitochondria of rat heart. Gen Physiol Biophys 32, 415-420.

15. Sohal RS, Arnold LA \& Sohal BH (1990) Age-related changes in antioxidant enzymes and prooxidant generation in tissues of the rat with special reference to parameters in two insect species. Free Radic Biol Med 9, 495-500.

16. Zhang H, Davies KJA \& Forman HJ (2015) Oxidative stress response and Nrf2 signaling in aging. Free Radic Biol Med 88, 314-336.

17. Pansarasa O, Bertorelli L, Vecchiet J, et al. (1999) Agedependent changes of antioxidant activities and markers of free radical damage in human skeletal muscle. Free Radic Biol Med 27, 617-622.

18. Stojkovski V, Hadzi-Petrushev N, Ilieski V, et al. (2013) Age and heat exposure-dependent changes in antioxidant enzymes activities in rat's liver and brain mitochondria: role of $\alpha$-tocopherol. Physiol Res 62, 503-510.

19. Zhang HJ, Xu L, Drake VJ, et al. (2003) Heat-induced liver injury in old rats is associated with exaggerated oxidative stress and altered transcription factor activation. FASEB J 17, 2293-2295.

20. Cummings BP, Stanhope KL, Graham JL, et al. (2010) Dietary fructose accelerates the development of diabetes in UCDT2DM rats: amelioration by the antioxidant, $\alpha$-lipoic acid. $A m J$ Physiol Regul Integr Comp Physiol 298, R1343-R1350.

21. Girard A, Madani S, Boukortt F, et al. (2006) Fructoseenriched diet modifies antioxidant status and lipid metabolism in spontaneously hypertensive rats. Nutrition 22, 758-766.
22. Ruiz-Ramírez A, Chávez-Salgado M, Peñeda-Flores JA, et al. (2011) High-sucrose diet increases ROS generation, FFA accumulation, UCP2 level, and proton leak in liver mitochondria. Am J Physiol Endocrinol Metab 301, E1198-E1207.

23. Francini F, Castro MC, Schinella G, et al. (2010) Changes induced by a fructose-rich diet on hepatic metabolism and the antioxidant system. Life Sci 86, 965-971.

24. Thirunavukkarasu V, Anitha Nandhini AT \& Anuradha CV (2004) Cardiac lipids and antioxidant status in high fructose rats and the effect of $\alpha$-lipoic acid. Nutr Metab Cardiovasc Dis 14, 351-357.

25. Busserolles J, Rock E, Gueux E, et al. (2002) Short-term consumption of a high-sucrose diet has a pro-oxidant effect in rats. BrJ Nutr $\mathbf{8 7}, 337-342$.

26. Jaiswal N, Maurya CK, Pandey J, et al. (2015) Fructose-induced ROS generation impairs glucose utilization in L6 skeletal muscle cells. Free Radic Res 49, 1055-1068.

27. Almenara CCP, Mill JG, Vassallo DV, et al. (2015) In vitro fructose exposure overactivates NADPH oxidase and causes oxidative stress in the isolated rat aorta. Toxicol In Vitro 29, 2030-2037.

28. Sanders YY, Liu H, Liu G, et al. (2015) Epigenetic mechanisms regulate NADPH oxidase-4 expression in cellular senescence. Free Radic Biol Med 79, 197-205.

29. Cannizzo B, Luján A, Estrella N, et al. (2012) Insulin resistance promotes early atherosclerosis via increased proinflammatory proteins and oxidative stress in fructosefed ApoE-KO mice. Exp Diabetes Res 2012, e941304.

30. Semba RD, Nicklett EJ \& Ferrucci L (2010) Does accumulation of advanced glycation end products contribute to the aging phenotype? J Gerontol A Biol Sci Med Sci 65A, 963-975.

31. Haus JM, Carrithers JA, Trappe SW, et al. (2007) Collagen, cross-linking, and advanced glycation end products in aging human skeletal muscle. J Appl Physiol 103, 2068-2076.

32. Kimur T, Takamatsu J, Ikeda K, et al. (1996) Accumulation of advanced glycation end products of the Maillard reaction with age in human hippocampal neurons. Neurosci Lett 208, $53-56$.

33. Odetti P, Rossi S, Monacelli F, et al. (2005) Advanced glycation end products and bone loss during aging. Ann N Y Acad Sci 1043, 710-717.

34. Sitte N, Merker K \& Grune T (1998) Proteasome-dependent degradation of oxidized proteins in MRC-5 fibroblasts. FEBS Lett 440, 399-402.

35. McPherson JD, Shilton BH \& Walton DJ (1988) Role of fructose in glycation and cross-linking of proteins. Biochemistry (Mosc) 27, 1901-1907.

36. Suárez G, Rajaram R, Oronsky AL, et al. (1989) Nonenzymatic glycation of bovine serum albumin by fructose (fructation). Comparison with the Maillard reaction initiated by glucose. J Biol Chem 264, 3674-3679.

37. Semchyshyn HM, Lozinska LM, Miedzobrodzki J, et al. (2011) Fructose and glucose differentially affect aging and carbonyl/oxidative stress parameters in Saccharomyces cerevisiae cells. Carbohydr Res 346, 933-938.

38. Luevano-Contreras C \& Chapman-Novakofski K (2010) Dietary advanced glycation end products and aging. Nutrients 2, 1247-1265.

39. Ott C, Jacobs K, Haucke E, et al. (2014) Role of advanced glycation end products in cellular signaling. Redox Biol 2, 411-429. 
40. Levi B \& Werman MJ (1998) Long-term fructose consumption accelerates glycation and several age-related variables in male rats. $J$ Nutr $\mathbf{1 2 8}, 1442-1449$.

41. Mastrocola R, Collino M, Rogazzo M, et al. (2013) Advanced glycation end products promote hepatosteatosis by interfering with SCAP-SREBP pathway in fructosedrinking mice. Am J Physiol Gastrointest Liver Physiol 305, G398-G407.

42. Ballou SP, Lozanski GB, Hodder S, et al. (1996) Quantitative and qualitative alterations of acute-phase proteins in healthy elderly persons. Age Ageing 25, 224-230.

43. Bruunsgaard H, Andersen-Ranberg K, Jeune B, et al. (1999) A high plasma concentration of TNF- $\alpha$ is associated with dementia in centenarians. J Gerontol A Biol Sci Med Sci 54, M357-M364.

44. Roubenoff R, Harris TB, Abad LW, et al. (1998) Monocyte cytokine production in an elderly population: effect of age and inflammation. J Gerontol A Biol Sci Med Sci 53A, M20-M26.

45. Wei J, Xu H, Davies JL, et al. (1992) Increase of plasma IL-6 concentration with age in healthy subjects. Life Sci 51, 1953-1956.

46. Franceschi C, Bonafè M, Valensin S, et al. (2000) Inflammaging. An evolutionary perspective on immunosenescence. Ann N Y Acad Sci $\mathbf{9 0 8}, 244-254$.

47. Franceschi C \& Campisi J (2014) Chronic inflammation (inflammaging) and its potential contribution to ageassociated diseases. J Gerontol A Biol Sci Med Sci 69, S4-S9.

48. Salvioli S, Monti D, Lanzarini C, et al. (2013) Immune system, cell senescence, aging and longevity - inflammaging reappraised. Curr Pharm Des 19, 1675-1679.

49. Singh $\mathrm{T} \&$ \& Newman $\mathrm{AB}$ (2011) Inflammatory markers in population studies of aging. Ageing Res Rev 10, 319-329.

50. Roglans N, Vilà L, Farré M, et al. (2007) Impairment of hepatic Stat-3 activation and reduction of PPAR $\alpha$ activity in fructose-fed rats. Hepatology 45, 778-788.

51. Hu Q-H, Zhang X, Pan Y, et al. (2012) Allopurinol, quercetin and rutin ameliorate renal NLRP3 inflammasome activation and lipid accumulation in fructose-fed rats. Biochem Pharmacol 84, 113-125.

52. Kawamura T, Yoshida K, Sugawara A, et al. (2002) Impact of exercise and angiotensin converting enzyme inhibition on tumor necrosis factor- $\alpha$ and leptin in fructose-fed hypertensive rats. Hypertens Res 25, 919-926.

53. Vasiljević A, Bursać B, Djordjevic A, et al. (2014) Hepatic inflammation induced by high-fructose diet is associated with altered 11ßHSD1 expression in the liver of Wistar rats. Eur J Nutr 53, 1393-1402.

54. Jameel F, Phang M, Wood LG, et al. (2014) Acute effects of feeding fructose, glucose and sucrose on blood lipid levels and systemic inflammation. Lipids Health Dis 13, 195.

55. Aeberli I, Gerber PA, Hochuli M, et al. (2011) Low to moderate sugar-sweetened beverage consumption impairs glucose and lipid metabolism and promotes inflammation in healthy young men: a randomized controlled trial. $\mathrm{Am} \mathrm{J}$ Clin Nutr 94, 479-485.

56. Liu S, Manson JE, Buring JE, et al. (2002) Relation between a diet with a high glycemic load and plasma concentrations of high-sensitivity C-reactive protein in middle-aged women. Am J Clin Nutr 75, 492-498.

57. Chavakis T, Bierhaus A \& Nawroth PP (2004) RAGE (receptor for advanced glycation end products): a central player in the inflammatory response. Microbes Infect $\mathbf{6}$, $1219-1225$.
58. Gaens KHJ, Niessen PMG, Rensen SS, et al. (2012) Endogenous formation of $N^{\varepsilon}$-(carboxymethyl)lysine is increased in fatty livers and induces inflammatory markers in an in vitro model of hepatic steatosis. J Hepatol 56, 647-655.

59. Ferrara A, Barrett-Connor E \& Shan J (1997) Total, LDL, and HDL cholesterol decrease with age in older men and women. The Rancho Bernardo Study 1984-1994. Circulation 96, 37-43.

60. Park Y-MM, Sui X, Liu J, et al. (2015) The effect of cardiorespiratory fitness on age-related lipids and lipoproteins. J Am Coll Cardiol 65, 2091-2100.

61. Vaarhorst AAM, Beekman M, Suchiman EHD, et al. (2011) Lipid metabolism in long-lived families: the Leiden Longevity Study. Age 33, 219-227.

62. Al-Rasheed N, Al-Rasheed N, Bassiouni Y, et al. (2014) Potential protective effects of Nigella sativa and Allium sativum against fructose-induced metabolic syndrome in rats. J Oleo Sci 63, 839-848.

63. Kazumi T, Odaka H, Hozumi T, et al. (1997) Effects of dietary fructose or glucose on triglyceride production and lipogenic enzyme activities in the liver of Wistar fatty rats, an animal model of NIDDM. Endocr J 44, 239-245.

64. Catena C, Giacchetti G, Novello M, et al. (2003) Cellular mechanisms of insulin resistance in rats with fructoseinduced hypertension. Am J Hypertens 16, 973-978.

65. D'Alessandro ME, Chicco A \& Lombardo YB (2013) Fish oil reverses the altered glucose transporter, phosphorylation, insulin receptor substrate- 1 protein level and lipid contents in the skeletal muscle of sucrose-rich diet fed rats. Prostaglandins Leukot Essent Fatty Acids 88, 171-177.

66. Schultz A, Neil D, Aguila MB, et al. (2013) Hepatic adverse effects of fructose consumption independent of overweight/obesity. Int J Mol Sci 14, 21873-21886.

67. Bantle JP, Raatz SK, Thomas W, et al. (2000) Effects of dietary fructose on plasma lipids in healthy subjects. $A m J$ Clin Nutr 72, 1128-1134.

68. Teff KL, Elliott SS, Tschöp M, et al. (2004) Dietary fructose reduces circulating insulin and leptin, attenuates postprandial suppression of ghrelin, and increases triglycerides in women. J Clin Endocrinol Metab 89, 2963-2972.

69. Maersk M, Belza A, Stødkilde-Jørgensen H, et al. (2012) Sucrose-sweetened beverages increase fat storage in the liver, muscle, and visceral fat depot: a 6-mo randomized intervention study. Am J Clin Nutr 95, 283-289.

70. Oliveira LSC, Santos DA, Barbosa-da-Silva S, et al. (2014) The inflammatory profile and liver damage of a sucroserich diet in mice. J Nutr Biochem 25, 193-200.

71. Yang M-H, Wang C-H \& Chen H-L (2001) Green, oolong and black tea extracts modulate lipid metabolism in hyperlipidemia rats fed high-sucrose diet. J Nutr Biochem 12, $14-20$.

72. Lowndes J, Sinnett S, Yu Z, et al. (2014) The effects of fructose-containing sugars on weight, body composition and cardiometabolic risk factors when consumed at up to the 90th percentile population consumption level for fructose. Nutrients 6, 3153-3168.

73. Fink RI, Kolterman OG, Griffin J, et al. (1983) Mechanisms of insulin resistance in aging. J Clin Invest $\mathbf{7 1}$, $1523-1535$.

74. Rowe JW, Minaker KL, Pallotta JA, et al. (1983) Characterization of the insulin resistance of aging. J Clin Invest $\mathbf{7 1}$, 1581-1587.

75. Seo E, Kim S, Lee SJ, et al. (2015) Ginseng berry extract supplementation improves age-related decline of insulin signaling in mice. Nutrients 7, 3038-3053. 
76. Houmard JA, Weidner MD, Dolan PL, et al. (1995) Skeletal muscle GLUT4 protein concentration and aging in humans. Diabetes 44, 555-560.

77. Amati F, Dubé JJ, Coen PM, et al. (2009) Physical inactivity and obesity underlie the insulin resistance of aging. Diabetes Care 32, 1547-1549.

78. Nishimura H, Kuzuya H, Okamoto M, et al. (1988) Change of insulin action with aging in conscious rats determined by euglycaemic clamp. Am J Physiol Endocrinol Metab 254, E92-E98.

79. Soriguer F, Colomo N, Valdés S, et al. (2014) Modifications of the homeostasis model assessment of insulin resistance index with age. Acta Diabetol 51, 917-925.

80. Geloneze B, de Oliveira M da S, Vasques ACJ, et al. (2014) Impaired incretin secretion and pancreatic dysfunction with older age and diabetes. Metabolism 63, 922-929.

81. Ihm S-H, Matsumoto I, Sawada T, et al. (2006) Effect of donor age on function of isolated human islets. Diabetes 55, 1361-1368.

82. Szoke E, Shrayyef MZ, Messing S, et al. (2008) Effect of aging on glucose homeostasis accelerated deterioration of $\beta$-cell function in individuals with impaired glucose tolerance. Diabetes Care 31, 539-543.

83. Cohen AM \& Teitelbaum A (1964) Effect of dietary sucrose and starch on oral glucose tolerance and insulin-like activity. Am J Physiol 206, 105-108.

84. Gibson S, Gunn P, Wittekind A, et al. (2013) The effects of sucrose on metabolic health: a systematic review of human intervention studies in healthy adults. Crit Rev Food Sci Nutr 53, 591-614.

85. Faeh D, Minehira K, Schwarz J-M, et al. (2005) Effect of fructose overfeeding and fish oil administration on hepatic de novo lipogenesis and insulin sensitivity in healthy men. Diabetes 54, 1907-1913.

86. Black RNA, Spence M, McMahon RO, et al. (2006) Effect of eucaloric high- and low-sucrose diets with identical macronutrient profile on insulin resistance and vascular risk: a randomized controlled trial. Diabetes 55, 3566-3572.

87. Thorburn AW, Storlien LH, Jenkins AB, et al. (1989) Fructose-induced in vivo insulin resistance and elevated plasma triglyceride levels in rats. Am J Clin Nutr 49, $1155-1163$

88. Martinez FJ, Rizza RA \& Romero JC (1994) High-fructose feeding elicits insulin resistance, hyperinsulinism, and hypertension in normal mongrel dogs. Hypertension 23, 456-463.

89. Pamies-Andreu E, Fiksen-Olsen M, Rizza RA, et al. (1995) High-fructose feeding elicits insulin resistance without hypertension in normal mongrel dogs. Am J Hypertens $\mathbf{8}$, $732-738$.

90. Stanhope KL, Schwarz JM, Keim NL, et al. (2009) Consuming fructose-sweetened, not glucose-sweetened, beverages increases visceral adiposity and lipids and decreases insulin sensitivity in overweight/obese humans. J Clin Invest 119, 1322-1334.

91. Teff KL, Elliott SS, Tschöp M, et al. (2004) Dietary fructose reduces circulating insulin and leptin, attenuates postprandial suppression of ghrelin, and increases triglycerides in women. J Clin Endocrinol Metab 89, 2963-2972.

92. Storlien LH, Kraegen EW, Jenkins AB, et al. (1988) Effects of sucrose vs starch diets on in vivo insulin action, thermogenesis, and obesity in rats. Am J Clin Nutr 47, 420-427.

93. Tobey TA, Mondon CE, Zavaroni I, et al. (1982) Mechanism of insulin resistance in fructose-fed rats. Metabolism 31, 608-612.
94. Chun M-R, Lee YJ, Kim K-H, et al. (2010) Differential effects of high-carbohydrate and high-fat diet composition on muscle insulin resistance in rats. J Korean Med Sci $\mathbf{2 5}$, 1053-1059.

95. Pagliassotti MJ \& Prach PA (1995) Quantity of sucrose alters the tissue pattern and time course of insulin resistance in young rats. Am J Physiol Regul Integr Comp Physiol 269, R641-R646.

96. Pagliassotti MJ, Shahrokhi KA \& Moscarello M (1994) Involvement of liver and skeletal muscle in sucroseinduced insulin resistance: dose-response studies. $A m$ J Physiol 266, R1637-R1644.

97. Vrána A \& Kazdová L (1970) Insulin sensitivity of rat adipose tissue and of diaphragm in vitro: effect of the type of dietary carbohydrate (starch-sucrose). Life Sci 9, 257-265.

98. Oudot A, Behr-Roussel D, Compagnie S, et al. (2009) Endothelial dysfunction in insulin-resistant rats is associated with oxidative stress and COX pathway dysregulation. Physiol Res 58, 499-509.

99. Khanal RC, Howard LR, Wilkes SE, et al. (2010) Cranberry pomace partially ameliorates metabolic factors associated with high fructose feeding in growing SpragueDawley rats. J Funct Foods 2, 284-291.

100. Shimomura I, Matsuda M, Hammer RE, et al. (2000) Decreased IRS-2 and increased SREBP-1c lead to mixed insulin resistance and sensitivity in livers of lipodystrophic and ob/ob mice. Mol Cell 6, 77-86.

101. Pan DA, Lillioja S, Kriketos AD, et al. (1997) Skeletal muscle triglyceride levels are inversely related to insulin action. Diabetes 46, 983-988.

102. Seppälä-Lindroos A, Vehkavaara S, Häkkinen A-M, et al. (2002) Fat accumulation in the liver is associated with defects in insulin suppression of glucose production and serum free fatty acids independent of obesity in normal men. J Clin Endocrinol Metab 87, 3023-3028.

103. Morino K, Petersen KF \& Shulman GI (2006) Molecular mechanisms of insulin resistance in humans and their potential links with mitochondrial dysfunction. Diabetes 55, S9-S15.

104. Monetti M, Levin MC, Watt MJ, et al. (2007) Dissociation of hepatic steatosis and insulin resistance in mice overexpressing DGAT in the liver. Cell Metab 6, 69-78.

105. Sun Z \& Lazar MA (2013) Dissociating fatty liver and diabetes. Trends Endocrinol Metab 24, 4-12.

106. Takeuchi M, Takino J-I, Sakasai-Sakai A, et al. (2014) Involvement of the TAGE-RAGE system in non-alcoholic steatohepatitis: novel treatment strategies. World J Hepatol 6, 880-893

107. Aguirre V, Werner ED, Giraud J, et al. (2002) Phosphorylation of $\mathrm{Ser}^{307}$ in insulin receptor substrate-1 blocks interactions with the insulin receptor and inhibits insulin action. $J$ Biol Chem 277, 1531-1537.

108. Paz K, Hemi R, LeRoith D, et al. (1997) A molecular basis for insulin resistance elevated serine/threonine phosphorylation of IRS-1 and IRS-2 inhibits their binding to the juxtamembrane region of the insulin receptor and impairs their ability to undergo insulin-induced tyrosine phosphorylation. J Biol Chem 272, 29911-29918.

109. Aguirre V, Uchida T, Yenush L, et al. (2000) The c-Jun $\mathrm{NH}_{2^{-}}$ terminal kinase promotes insulin resistance during association with insulin receptor substrate-1 and phosphorylation of Ser ${ }^{307}$. J Biol Chem 275, 9047-9054.

110. Wei Y \& Pagliassotti MJ (2004) Hepatospecific effects of fructose on c-Jun $\mathrm{NH}_{2}$-terminal kinase: implications for hepatic insulin resistance. Am J Physiol Endocrinol Metab 287, E926-E933. 
111. Zhu Y, Hu Y, Huang T, et al. (2014) High uric acid directly inhibits insulin signalling and induces insulin resistance. Biochem Biophys Res Commun 447, 707-714.

112. Sheedfar F, Biase SD, Koonen D, et al. (2013) Liver diseases and aging: friends or foes? Aging Cell 12, 950-954.

113. Bertolotti M, Lonardo A, Mussi C, et al. (2014) Nonalcoholic fatty liver disease and aging: epidemiology to management. World J Gastroenterol 20, 14185-14204.

114. Softic S, Cohen DE \& Kahn CR (2016) Role of dietary fructose and hepatic de novo lipogenesis in fatty liver disease. Dig Dis Sci 61, 1282-1293.

115. Abdelmalek MF, Suzuki A, Guy C, et al. (2010) Increased fructose consumption is associated with fibrosis severity in patients with NAFLD. Hepatology 51, 1961-1971.

116. Ouyang X, Cirillo P, Sautin Y, et al. (2008) Fructose consumption as a risk factor for non-alcoholic fatty liver disease. J Hepatol 48, 993-999.

117. Thuy S, Ladurner R, Volynets V, et al. (2008) Nonalcoholic fatty liver disease in humans is associated with increased plasma endotoxin and plasminogen activator inhibitor 1 concentrations and with fructose intake. J Nutr 138, 1452-1455.

118. Lê K-A, Ith M, Kreis R, et al. (2009) Fructose overconsumption causes dyslipidemia and ectopic lipid deposition in healthy subjects with and without a family history of type 2 diabetes. Am J Clin Nutr 89, 1760-1765.

119. Ishimoto T, Lanaspa MA, Rivard CJ, et al. (2013) High fat and high sucrose (Western) diet induce steatohepatitis that is dependent on fructokinase. Hepatology 58, 1632-1643.

120. Lanaspa MA, Sanchez-Lozada LG, Choi Y-J, et al. (2012) Uric acid induces hepatic steatosis by generation of mitochondrial oxidative stress: potential role in fructosedependent and -independent fatty liver. J Biol Chem 287, 40732-40744.

121. Lanaspa MA, Sanchez-Lozada LG, Cicerchi C, et al. (2012) Uric acid stimulates fructokinase and accelerates fructose metabolism in the development of fatty liver. PLOS ONE $\mathbf{7}$, e47948.

122. Leung C, Herath CB, Jia Z, et al. (2014) Dietary glycotoxins exacerbate progression of experimental fatty liver disease. I Hepatol 60, 832-838.

123. Mastrocola R, Nigro D, Chiazza F, et al. (2016) Fructosederived advanced glycation end-products drive lipogenesis and skeletal muscle reprogramming via SREBP-1c dysregulation in mice. Free Radic Biol Med 91, 224-235.

124. Tilg $\mathrm{H} \&$ Moschen $\mathrm{AR}$ (2008) Insulin resistance, inflammation, and non-alcoholic fatty liver disease. Trends Endocrinol Metab 19, 371-379.

125. Pagliassotti MJ, Prach PA, Koppenhafer TA, et al. (1996) Changes in insulin action, triglycerides, and lipid composition during sucrose feeding in rats. Am J Physiol Regul Integr Comp Physiol 271, R1319-R1326.

126. Aparicio-Vergara M, Hommelberg PPH, Schreurs M, et al. (2013) Tumor necrosis factor receptor 1 gain-of-function mutation aggravates nonalcoholic fatty liver disease but does not cause insulin resistance in a murine model. Hepatology 57, 566-576

127. Lírio LM, Forechi L, Zanardo TC, et al. (2016) Chronic fructose intake accelerates non-alcoholic fatty liver disease in the presence of essential hypertension. $J$ Diabetes Complications 30, 85-92.

128. Vasan RS, Beiser A, Seshadri S, et al. (2002) Residual lifetime risk for developing hypertension in middle-aged women and men: the Framingham Heart Study. JAMA 287, 1003-1010.
129. Buford TW (2016) Hypertension and aging. Ageing Res Rev 26, 96-111.

130. Kaess BM, Rong J, Larson MG, et al. (2012) Aortic stiffness, blood pressure progression, and incident hypertension. JAMA 308, 875-881.

131. Sell DR \& Monnier VM (2012) Molecular basis of arterial stiffening: role of glycation - a mini-review. Gerontology 58, 227-237.

132. Xu B, Chibber R, Ruggiero D, et al. (2003) Impairment of vascular endothelial nitric oxide synthase activity by advanced glycation end products. FASEB J 17, 1289-1291.

133. Rojas A, Romay S, González D, et al. (2000) Regulation of endothelial nitric oxide synthase expression by albuminderived advanced glycosylation end products. Circ Res $\mathbf{8 6}$, e50-e54.

134. Linden E, Cai W, He JC, et al. (2008) Endothelial dysfunction in patients with chronic kidney disease results from advanced glycation end products (AGE)-mediated inhibition of endothelial nitric oxide synthase through RAGE activation. Clin J Am Soc Nephrol 3, 691-698.

135. Soro-Paavonen A, Zhang W-Z, Venardos K, et al. (2010) Advanced glycation end-products induce vascular dysfunction via resistance to nitric oxide and suppression of endothelial nitric oxide synthase. J Hypertens 28, 780-788.

136. Hwang IS, Ho H, Hoffman BB, et al. (1987) Fructoseinduced insulin resistance and hypertension in rats. Hypertension 10, 512-516.

137. D'Angelo G, Elmarakby AA, Pollock DM, et al. (2005) Fructose feeding increases insulin resistance but not blood pressure in Sprague-Dawley rats. Hypertension $\mathbf{4 6}$, 806-811.

138. Park SK \& Meyer TW (1992) The effects of fructose feeding on glomerular structure in the rat. J Am Soc Nephrol 3, 1330-1332.

139. Takagawa Y, Berger ME, Hori MT, et al. (2001) Long-term fructose feeding impairs vascular relaxation in rat mesenteric arteries. Am J Hypertens 14, 811-817.

140. Jalal DI, Smits G, Johnson RJ, et al. (2010) Increased fructose associates with elevated blood pressure. J Am Soc Nephrol 21, 1543-1549.

141. Soleimani M (2011) Dietary fructose, salt absorption and hypertension in metabolic syndrome: towards a new paradigm. Acta Physiol 201, 55-62.

142. Bhanot S, McNeill JH \& Bryer-Ash M (1994) Vanadyl sulfate prevents fructose-induced hyperinsulinemia and hypertension in rats. Hypertension $\mathbf{2 3}, 308-312$.

143. Ikeda T, Gomi T, Hirawa N, et al. (1996) Improvement of insulin sensitivity contributes to blood pressure reduction after weight loss in hypertensive subjects with obesity. Hypertension 27, 1180-1186.

144. Verma S, Yao L, Dumont AS, et al. (2000) Metformin treatment corrects vascular insulin resistance in hypertension. J Hypertens 18, 1445-1450.

145. Xing W, Li Y, Zhang $\mathrm{H}$, et al. (2013) Improvement of vascular insulin sensitivity by downregulation of GRK2 mediates exercise-induced alleviation of hypertension in spontaneously hypertensive rats. Am J Physiol Heart Circ Physiol 305, H1111-H1119.

146. Tran LT, Yuen VG \& McNeill JH (2009) The fructose-fed rat: a review on the mechanisms of fructose-induced insulin resistance and hypertension. Mol Cell Biochem 332, 145-159.

147. Li L-X, Dong X-H, Li M-F, et al. (2015) Serum uric acid levels are associated with hypertension and metabolic syndrome but not atherosclerosis in Chinese inpatients with type 2 diabetes. J Hypertens 33, 482-490. 
148. Mellen PB, Bleyer AJ, Erlinger TP, et al. (2006) Serum uric acid predicts incident hypertension in a biethnic cohort the atherosclerosis risk in communities study. Hypertension $\mathbf{4 8}$, 1037-1042.

149. Perlstein TS, Gumieniak O, Williams GH, et al. (2006) Uric acid and the development of hypertension: The Normative Aging Study. Hypertension 48, 1031-1036.

150. Khosla UM, Zharikov S, Finch JL, et al. (2005) Hyperuricemia induces endothelial dysfunction. Kidney Int $\mathbf{6 7}$, 1739-1742.

151. Nakagawa T, Hu H, Zharikov S, et al. (2006) A causal role for uric acid in fructose-induced metabolic syndrome. $A m J$ Physiol Renal Physiol 290, F625-F631.

152. Park DC \& Reuter-Lorenz P (2009) The adaptive brain: aging and neurocognitive scaffolding. Annu Rev Psychol 60, 173-196.

153. Aagaard P, Suetta C, Caserotti P, et al. (2010) Role of the nervous system in sarcopenia and muscle atrophy with aging: strength training as a countermeasure. Scand J Med Sci Sports 20, 49-64.

154. Harada CN, Natelson Love MC \& Triebel K (2013) Normal cognitive aging. Clin Geriatr Med 29, 737-752.

155. Dickstein DL, Kabaso D, Rocher AB, et al. (2007) Changes in the structural complexity of the aged brain. Aging Cell $\mathbf{6}$, 275-284.

156. Resnick SM, Pham DL, Kraut MA, et al. (2003) Longitudinal magnetic resonance imaging studies of older adults: a shrinking brain. J Neurosci 23, 3295-3301.

157. Crouch PJ, Harding S-ME, White AR, et al. (2008) Mechanisms of $\mathrm{A} \beta$ mediated neurodegeneration in Alzheimer's disease. Int J Biochem Cell Biol 40, 181-198.

158. Madden DJ, Spaniol J, Costello MC, et al. (2009) Cerebral white matter integrity mediates adult age differences in cognitive performance. J Cogn Neurosci 21, 289-302.

159. Rogalski E, Stebbins GT, Barnes CA, et al. (2012) Agerelated changes in parahippocampal white matter integrity: a diffusion tensor imaging study. Neuropsychologia 50, 1759-1765.

160. Ye X, Gao X, Scott T, et al. (2011) Habitual sugar intake and cognitive function among middle-aged and older Puerto Ricans without diabetes. Br J Nutr 106, 1423-1432.

161. Ross AP, Bartness TJ, Mielke JG, et al. (2009) A high fructose diet impairs spatial memory in male rats. Neurobiol Learn Mem 92, 410-416.

162. Cisternas P, Salazar P, Serrano FG, et al. (2015) Fructose consumption reduces hippocampal synaptic plasticity underlying cognitive performance. Biochim Biophys Acta 1852, 2379-2390.

163. Jurdak N, Lichtenstein AH \& Kanarek RB (2008) Dietinduced obesity and spatial cognition in young male rats. Nutr Neurosci 11, 48-54.

164. Jurdak N \& Kanarek RB (2009) Sucrose-induced obesity impairs novel object recognition learning in young rats. Physiol Behav 96, 1-5.

165. Meng Q, Ying Z, Noble E, et al. (2016) Systems nutrigenomics reveals brain gene networks linking metabolic and brain disorders. EBioMedicine 7, 157-166.

166. Mielke JG, Taghibiglou C, Liu L, et al. (2005) A biochemical and functional characterization of diet-induced brain insulin resistance. J Neurochem $\mathbf{9 3}, 1568-1578$.

167. Agrawal R \& Gomez-Pinilla F (2012) "Metabolic syndrome" in the brain: deficiency in omega-3 fatty acid exacerbates dysfunctions in insulin receptor signalling and cognition. J Physiol 590, 2485-2499.

168. Noble W, Planel E, Zehr C, et al. (2005) Inhibition of glycogen synthase kinase-3 by lithium correlates with reduced tauopathy and degeneration in vivo. Proc Natl Acad Sci U S A 102, 6990-6995.

169. Schubert M, Gautam D, Surjo D, et al. (2004) Role for neuronal insulin resistance in neurodegenerative diseases. Proc Natl Acad Sci U S A 101, 3100-3105.

170. Ho L, Qin W, Pompl PN, et al. (2004) Diet-induced insulin resistance promotes amyloidosis in a transgenic mouse model of Alzheimer's disease. FASEB J 18, 902-904.

171. Carvalho C, Cardoso S, Correia SC, et al. (2012) Metabolic alterations induced by sucrose intake and Alzheimer's disease promote similar brain mitochondrial abnormalities. Diabetes 61, 1234-1242.

172. Hsu TM, Konanur VR, Taing L, et al. (2015) Effects of sucrose and high fructose corn syrup consumption on spatial memory function and hippocampal neuroinflammation in adolescent rats. Hippocampus 25, 227-239.

173. Beilharz JE, Maniam J \& Morris MJ (2014) Short exposure to a diet rich in both fat and sugar or sugar alone impairs place, but not object recognition memory in rats. Brain Behav Immun 37, 134-141.

174. Erbaş O, Solmaz V, Aksoya D, et al. (2014) Cholecalciferol (vitamin D 3) improves cognitive dysfunction and reduces inflammation in a rat fatty liver model of metabolic syndrome. Life Sci 103, 68-72.

175. Engelhart MJ, Geerlings MI, Meijer J, et al. (2004) Inflammatory proteins in plasma and the risk of dementia: The Rotterdam Study. Arch Neurol 61, 668-672.

176. Teunissen CE, van Boxtel MPJ, Bosma H, et al. (2003) Inflammation markers in relation to cognition in a healthy aging population. J Neuroimmunol 134, 142-150.

177. Weaver JD, Huang M-H, Albert M, et al. (2002) Interleukin6 and risk of cognitive decline: MacArthur Studies of Successful Aging. Neurology 59, 371-378.

178. Yaffe K, Lindquist K, Penninx BW, et al. (2003) Inflammatory markers and cognition in well-functioning AfricanAmerican and white elders. Neurology 61, 76-80.

179. Erbaş O, Akseki HS, Aktuğ $\mathrm{H}$, et al. (2015) Low-grade chronic inflammation induces behavioral stereotypy in rats. Metab Brain Dis 30, 739-746.

180. López M, Varela L, Vázquez MJ, et al. (2010) Hypothalamic AMPK and fatty acid metabolism mediate thyroid regulation of energy balance. Nat Med 16, 1001-1008.

181. Li J-M, Ge C-X, Xu M-X, et al. (2015) Betaine recovers hypothalamic neural injury by inhibiting astrogliosis and inflammation in fructose-fed rats. Mol Nutr Food Res 59, 189-202.

182. Li J, O W, Li W, et al. (2013) Oxidative stress and neurodegenerative disorders. Int J Mol Sci 14, $24438-24475$.

183. Coma M, Guix FX, Ill-Raga G, et al. (2008) Oxidative stress triggers the amyloidogenic pathway in human vascular smooth muscle cells. Neurobiol Aging 29, 969-980.

184. Su B, Wang X, Lee H, et al. (2010) Chronic oxidative stress causes increased tau phosphorylation in M17 neuroblastoma cells. Neurosci Lett 468, 267-271.

185. Smith MA, Taneda S, Richey PL, et al. (1994) Advanced Maillard reaction end products are associated with Alzheimer disease pathology. Proc Natl Acad Sci US A 91, 5710-5714.

186. Castellani R, Smith MA, Richey GL, et al. (1996) Glycoxidation and oxidative stress in Parkinson disease and diffuse Lewy body disease. Brain Res 737, 195-200.

187. Lüth H-J, Ogunlade V, Kuhla B, et al. (2005) Age- and stage-dependent accumulation of advanced glycation end products in intracellular deposits in normal and Alzheimer's disease. Brains Cereb Cortex 15, 211-220. 
188. Padmaraju V, Bhaskar JJ, Prasada Rao UJS, et al. (2011) Role of advanced glycation on aggregation and DNA binding properties of $\alpha$-synuclein. $J$ Alzheimers Dis 24, Suppl. 2, 211-221.

189. Vitek MP, Bhattacharya K, Glendening JM, et al. (1994) Advanced glycation end products contribute to amyloidosis in Alzheimer disease. Proc Natl Acad Sci U S 9 91, 4766-4770.

190. Ko S-Y, Lin Y-P, Lin Y-S, et al. (2010) Advanced glycation end products enhance amyloid precursor protein expression by inducing reactive oxygen species. Free Radic Biol Med 49, 474-480.

191. Von Haehling S, Morley JE \& Anker SD (2010) An overview of sarcopenia: facts and numbers on prevalence and clinical impact. J Cachexia Sarcopenia Muscle 1, 129-133.

192. Beaudart C, Reginster JY, Slomian J, et al. (2015) Estimation of sarcopenia prevalence using various assessment tools. Exp Gerontol 61, 31-37.

193. Dardevet D, Rémond D, Peyron M-A, et al. (2012) Muscle wasting and resistance of muscle anabolism: the 'anabolic threshold concept' for adapted nutritional strategies during sarcopenia. Sci World J 2012, 269531.

194. Mosoni L, Valluy MC, Serrurier B, et al. (1995) Altered response of protein synthesis to nutritional state and endurance training in old rats. Am $J$ Physiol 268 , E328-E335.

195. Mitchell WK, Wilkinson DJ, Phillips BE, et al. (2016) Human skeletal muscle protein metabolism responses to amino acid nutrition. Adv Nutr 7, 828S-838S.

196. Dardevet D, Sornet C, Balage M, et al. (2000) Stimulation of in vitro rat muscle protein synthesis by leucine decreases with age. J Nutr 130, 2630-2635.

197. Katsanos CS, Kobayashi H, Sheffield-Moore M, et al. (2005) Aging is associated with diminished accretion of muscle proteins after the ingestion of a small bolus of essential amino acids. Am J Clin Nutr 82, 1065-1073.

198. Timmerman KL, Lee JL, Dreyer HC, et al. (2010) Insulin stimulates human skeletal muscle protein synthesis via an indirect mechanism involving endothelialdependent vasodilation and mammalian target of rapamycin complex 1 signaling. J Clin Endocrinol Metab 95, 3848-3857.

199. Rasmussen BB, Fujita S, Wolfe RR, et al. (2006) Insulin resistance of muscle protein metabolism in aging. FASEB J 20, 768-769

200. Lee CG, Boyko EJ, Strotmeyer ES, et al. (2011) Association between insulin resistance and lean mass loss and fat mass gain in older men without diabetes mellitus. J Am Geriatr Soc 59, 1217-1224.

201. Lee CG, Boyko EJ, Barrett-Connor E, et al. (2011) Insulin sensitizers may attenuate lean mass loss in older men with diabetes. Diabetes Care 34, 2381-2386.

202. Marzani B, Balage M, Vénien A, et al. (2008) Antioxidant supplementation restores defective leucine stimulation of protein synthesis in skeletal muscle from old rats. $J$ Nutr 138, 2205-2211.

203. Balage M, Averous J, Rémond D, et al. (2010) Presence of low-grade inflammation impaired postprandial stimulation of muscle protein synthesis in old rats. J Nutr Biochem 21, 325-331.

204. Rieu I, Magne H, Savary-Auzeloux I, et al. (2009) Reduction of low grade inflammation restores blunting of postprandial muscle anabolism and limits sarcopenia in old rats. J Physiol 587, 5483-5492.

205. Gatineau E, Savary-Auzeloux I, Migné C, et al. (2015) Chronic intake of sucrose accelerates sarcopenia in older male rats through alterations in insulin sensitivity and muscle protein synthesis. J Nutr 145, 923-930.

206. Jaiswal N, Maurya CK, Arha D, et al. (2015) Fructose induces mitochondrial dysfunction and triggers apoptosis in skeletal muscle cells by provoking oxidative stress. Apoptosis 20, 930-947.

207. Phuwamongkolwiwat P, Suzuki T, Hira T, et al. (2014) Fructooligosaccharide augments benefits of quercetin-3$O-\beta$-glucoside on insulin sensitivity and plasma total cholesterol with promotion of flavonoid absorption in sucrose-fed rats. Eur J Nutr 53, 457-468.

208. NIH Consensus Development Panel on Osteoporosis Prevention, Diagnosis, and Therapy (2001) Osteoporosis prevention, diagnosis, and therapy. JAMA 285, 785-795.

209. National Osteoporosis Foundation (2002) America's Bone Health: The State of Osteoporosis and Low Bone Mass in Our Nation. Washington, DC: National Osteoporosis Foundation.

210. Pfeilschifter J (2003) Role of cytokines in postmenopausal bone loss. Curr Osteoporos Rep 1, 53-58.

211. McLean RR (2009) Proinflammatory cytokines and osteoporosis. Curr Osteoporos Rep 7, 134-139.

212. Dahl K, Ahmed LA, Joakimsen RM, et al. (2015) Highsensitivity C-reactive protein is an independent risk factor for non-vertebral fractures in women and men: The Troms $\varnothing$ Study. Bone 72, 65-70.

213. Liang B \& Feng Y (2011) The association of low bone mineral density with systemic inflammation in clinically stable COPD. Endocrine 42, 190-195.

214. de Pablo P, Cooper MS \& Buckley CD (2012) Association between bone mineral density and C-reactive protein in a large population-based sample. Arthritis Rheum 64, 2624-2631.

215. Wauquier F, Leotoing L, Coxam V, et al. (2009) Oxidative stress in bone remodelling and disease. Trends $\mathrm{Mol} \mathrm{Med}$ 15, 468-477.

216. Sharma T, Islam N, Ahmad J, et al. (2015) Correlation between bone mineral density and oxidative stress in postmenopausal women. Indian J Endocrinol Metab 19, 491-497.

217. Yang S, Feskanich D, Willett WC, et al. (2014) Association between global biomarkers of oxidative stress and hip fracture in postmenopausal women: a prospective study. J Bone Miner Res 29, 2577-2583.

218. Hanayama R, Shimizu H, Nakagami H, et al. (2009) Fluvastatin improves osteoporosis in fructose-fed insulin resistant model rats through blockade of the classical mevalonate pathway and antioxidant action. Int J Mol Med 23, 581-588.

219. Felice JI, Gangoiti MV, Molinuevo MS, et al. (2014) Effects of a metabolic syndrome induced by a fructose-rich diet on bone metabolism in rats. Metabolism 63, 296-305.

220. Bass EF, Baile CA, Lewis RD, et al. (2013) Bone quality and strength are greater in growing male rats fed fructose compared with glucose. Nutr Res 33, 1063-1071.

221. Jatkar A, Kurland IJ \& Judex S (2016) Diets high in fat or fructose differentially modulate bone health and lipid metabolism. Calcif Tissue Int 100, 20-28.

222. Gelfand RA \& Sherwin RS (1986) Nitrogen conservation in starvation revisited: protein sparing with intravenous fructose. Metabolism 35, 37-44.

223. Jackson AS, Janssen I, Sui X, et al. (2012) Longitudinal changes in body composition associated with healthy ageing: men, aged 20-96 years. Br J Nutr 107, 1085-1091.

224. Kiss C, Poór G, Donáth J, et al. (2003) Prevalence of obesity in an elderly Hungarian population. Eur J Epidemiol 18, 653-658. 
225. Bazzocchi A, Diano D, Ponti F, et al. (2013) Health and ageing: a cross-sectional study of body composition. Clin Nutr 32, 569-578.

226. Carter CS, Cesari M, Ambrosius WT, et al. (2004) Angiotensin-converting enzyme inhibition, body composition, and physical performance in aged rats. $J$ Gerontol $A$ Biol Sci Med Sci 59, B416-B423.

227. Kyle UG, Genton L, Hans D, et al. (2001) Age-related differences in fat-free mass, skeletal muscle, body cell mass and fat mass between 18 and 94 years. Eur J Clin Nutr $\mathbf{5 5}$, 663-672.

228. Mott JW, Wang J, Thornton JC, et al. (1999) Relation between body fat and age in 4 ethnic groups. Am J Clin Nutr 69, 1007-1013.

229. Bray GA, Nielsen SJ \& Popkin BM (2004) Consumption of high-fructose corn syrup in beverages may play a role in the epidemic of obesity. Am J Clin Nutr 79, 537-543.

230. Bray GA \& Popkin BM (2013) Calorie-sweetened beverages and fructose: what have we learned 10 years later. Pediatr Obes 8, 242-248.

231. Trumbo PR \& Rivers CR (2014) Systematic review of the evidence for an association between sugar-sweetened beverage consumption and risk of obesity. Nutr Rev $\mathbf{7 2}$, 566-574.

232. Dolan LC, Potter SM \& Burdock GA (2009) Evidence-based review on the effect of normal dietary consumption of fructose on development of hyperlipidemia and obesity in healthy, normal weight individuals. Crit Rev Food Sci Nutr 50, 53-84.

233. White C, Drummond S \& De Looy A (2010) Comparing advice to decrease both dietary fat and sucrose, or dietary fat only, on weight loss, weight maintenance and perceived quality of life. Int J Food Sci Nutr 61, 282-294.
234. Mooradian AD, Chehade J, Hurd R, et al. (2000) Monosaccharide-enriched diets cause hyperleptinemia without hypophagia. Nutrition 16, 439-441.

235. Shapiro A, Mu W, Roncal C, et al. (2008) Fructose-induced leptin resistance exacerbates weight gain in response to subsequent high-fat feeding. Am J Physiol Regul Integr Comp Physiol 295, R1370-R1375.

236. Lindqvist A, Baelemans A \& Erlanson-Albertsson C (2008) Effects of sucrose, glucose and fructose on peripheral and central appetite signals. Regul Pept 150, 26-32.

237. Yagi T, Ueda H, Amitani H, et al. (2012) The role of ghrelin, salivary secretions, and dental care in eating disorders. Nutrients 4, 967-989.

238. Hu Z, Cha SH, Chohnan S, et al. (2003) Hypothalamic malonyl-CoA as a mediator of feeding behavior. Proc Natl Acad Sci U S A 100, 12624-12629.

239. Wolfgang MJ, Cha SH, Sidhaye A, et al. (2007) Regulation of hypothalamic malonyl-CoA by central glucose and leptin. Proc Natl Acad Sci U S A 104, 19285-19290.

240. Cha SH, Wolfgang M, Tokutake Y, et al. (2008) Differential effects of central fructose and glucose on hypothalamic malonyl-CoA and food intake. Proc Natl Acad Sci U S A 105, 16871-16875.

241. Page KA, Chan O, Arora J, et al. (2013) EFfects of fructose vs glucose on regional cerebral blood flow in brain regions involved with appetite and reward pathways. JAMA 309, 63-70.

242. Murtagh-Mark CM, Reiser KM, Harris R, et al. (1995) Source of dietary carbohydrate affects life span of Fischer 344 rats independent of caloric restriction. J Gerontol A Biol Sci Med Sci 50A, B148-B154.

243. Ruff JS, Suchy AK, Hugentobler SA, et al. (2013) Humanrelevant levels of added sugar consumption increase female mortality and lower male fitness in mice. Nat Commun 4, 2245. 